1 This manuscript is a preprint to be submitted to Tectonics. This manuscript has not yet undergone 2 peer-review and subsequent versions of the manuscript may have different content. We welcome 3 feedback and invite you to contact the authors directly to comment on the manuscript. 


\section{Taking the pulse of salt-detached gravity \\ 5 gliding in the eastern Mediterranean}

Sian L. Evans ${ }^{1 *}$, Christopher A.-L. Jackson ${ }^{1}$ and Davide Oppo ${ }^{2}$

${ }^{1}$ Basins Research Group (BRG), Department of Earth Science \& Engineering, Imperial College, London, UK

${ }^{2}$ Sedimentary Basins Research Group, School of Geosciences, University of Louisiana at Lafayette, Lafayette, USA

*corresponding author: sian.evans15@imperial.ac.uk

\section{Abstract}

Despite having a profound impact on the structural evolution of salt-influenced basins, spatial and temporal variations in rates of salt flow, and their key controls, remain largely unconstrained. We investigate early-stage salt-detached gliding using a 3D seismic dataset from the Levant Margin in the Eastern Mediterranean, where gravitational instability due to margin uplift has caused northwestward translation of the Messinian salt sheet and its Plio-Pleistocene clastic overburden. Large, NE-trending, base-salt anticlines have allowed the basinward translation to be recorded by the development of supra-salt ramp syncline basins and fluid escape pipes, the latter forming due to the leakage of gas and fluid from the anticline crests. The trails of fluid escape pipes provide direct kinematic vectors of transport direction, while the stratigraphic record of the ramp syncline basins not only constrains the relative ages of the pipes, but allows us to quantify the magnitude of basinward translation. Correlating intra-RSB horizons across the margin provides relative age constraints, which we use to analyse lateral variations in translation rates along the margin, and how these vary through time. We show that translation rates are broadly uniform on the length scale of individual anticlines and related RSBs (c. $10 \mathrm{~km}$ ), but that there is significant margin-scale (c. $100 \mathrm{~km}$ ) lateral variability in both the direction and magnitude of translation. We attribute temporal variations in rates of translation to cyclical 'pulses' of salt flow due to volumetric flux imbalances across the anticlines, while the distribution of elastic strain in the overburden modulates the overall basin-scale trend. These results demonstrate the importance of local stresses in controlling the local direction and rate of salt flow at any point in time. 


\section{Introduction}

Salt-influenced basins and passive margins are structurally complex, globally distributed, and hydrocarbon-rich. The variety of structural styles in different salt basins around the world is testament to the myriad of ways in which salt-related deformation can affect the tectono-stratigraphic evolution of sedimentary basins. Over the past few decades seismic reflection data have transformed our understanding of subsurface salt tectonics, allowing us to investigate the regional structural evolution of salt basins (Jackson et al., 1994; Hudec and Jackson, 2007; Jackson and Hudec, 2017). However, the various controls on the evolution of these stress-sensitive systems are still debated. Gravity gliding and spreading are simplified end-member models used to describe gravitationally-driven salt tectonics along passive margins (e.g. Brun and Fort, 2011; Peel, 2014; Schultz-Ela, 2001), but the effects of other variables that introduce further complexity into the system, such as base-salt relief (e.g. Dooley et al., 2017; Pichel et al., 2019; Evans and Jackson, 2019) and intrasalt heterogeneity (e.g Albertz and Ings, 2012; Raith et al., 2016; Rowan et al., 2019), have remained poorly understood.

Due to the internally chaotic and low-amplitude appearance of salt bodies in seismic reflection data (Jones and Davison, 2014), the deformation history of seismically-imaged salt structures is commonly reconstructed using stratigraphic relationships and structures in the overburden (e.g. Quirk et al., 2012). While this approach is invaluable in reconstructing vertical salt movements (e.g. diapir growth), it often neglects that overburden structures may have also been laterally translated tens of $\mathrm{km}$ downdip. Estimations of lateral translation on salt-detached margins have relied heavily on summing extensional fault heaves (in the updip domain) and/or line-length balancing techniques (see Coleman et al., 2017). Typically, the 'undeformed' translational domain has yielded little information of use in this regard (Schultz-Ela, 2001).

Ramp syncline basins (RSBs) are one of the few stratigraphic features that record, and thus allow us to quantify, basinward translation of salt overburden (Jackson and Hudec, 2005). Although they were first recognised in the Gulf of Lyon, offshore France more than two decades ago (e.g. Benedicto et al., 1999), they are still often overlooked and under-utilised in many basins (Pichel et al., 2018). Saltdetached RSBs form as a result of salt and overburden translation across a sub-salt topographic high (Marton et al., 2000; Jackson and Hudec et al., 2005; Pichel et al., 2018; Evans and Jackson, 2019). This creates a local sediment depocentre adjacent to the high, above its downdip flank. Syn-kinematic strata thicken into this accommodation space, and onlap towards the updip high. As translation continues, the onlapping growth strata are progressively transported away from the high in the direction of salt flow. This creates an 'onlap surface' in the stratigraphic record, with the horizontal distance from the first onlap to the sub-salt high giving the total magnitude of translation (Jackson and 
Hudec, 2005). Recent studies have begun to exploit the uses of RSBs as records of translation on saltinfluenced passive margins, demonstrating how stacked RSBs of different ages may be used to reconstruct the history of salt-detached gravity gliding offshore Brazil (Pichel et al., 2018) and offshore Angola (Evans and Jackson, 2019).

Transient strain markers such as fluid escape pipes may also be used to reconstruct translation on saltinfluenced passive margins (Cartwright et al., 2018; Kirkham et al., 2019). The first study identified a trail of diachronous pipes in the deep Levantine Basin, offshore Lebanon, and determine that each pipe originated from the crest of a sub-salt anticline (termed the Oceanus structure; Fig. 1) before being transported basinward due to gravity gliding (Cartwright et al., 2018). A subsequent study then interpreted four distinct pipe trails originating from a single anticline nearby (termed the Saida-Tyr structure; Fig. 1) (Kirkham et al., 2019). By treating the pipes as direct kinematic markers the authors estimate the velocity of the overburden and viscosity of the deforming salt sheet. However, both studies are forced to make assumptions about the ages of the pipes, and they are limited to relatively small areas (each $<35 \mathrm{~km}^{2}$ ) due to the distribution of pipes, thus giving only local constraints on the kinematics of a much larger salt layer.

In this study we apply a new approach to investigating gravity-driven salt translation at the marginscale (covering an area of c. $5000 \mathrm{~km}^{2}$ ) by integrating the geological records given by RSBs and trails of fluid escape pipes. The young Messinian (latest Miocene) evaporite sequence of the Mediterranean Basin provides a perfect natural laboratory to study active, early-stage, gravity-driven salt tectonics of a thick salt sheet. We analyse eight RSBs and twelve associated fluid escape pipe trails in the updip domain of the northern Levantine Basin, offshore Lebanon. Because the Messinian salt giant is shallowly buried and only weakly deformed, it is well-imaged in seismic reflection data. Furthermore, unlike older basins (e.g. offshore Brazil and Angola), the RSBs are well-preserved and not yet overprinted by later tectonic deformation. They therefore provide an ideal opportunity to investigate early RSB development, quantify translation along the margin and assess implications for salt flow kinematics.

\section{Data and Methods}

We use a large (c. 10,000 km²) 3D seismic reflection dataset located offshore Lebanon in the northern Levantine Basin (Fig. 1) to investigate the stratigraphic record of RSBs in an area of early-stage gravity gliding. The dataset comprises a merge of seven time-migrated 3D seismic surveys acquired by PGS that have been processed to near-zero phase with reverse SEG polarity, i.e. an increase in acoustic impedance has a negative amplitude. Bin dimensions were $25 \times 25 \mathrm{~m}$ during data processing. The 
dominant frequencies of seismic data are $50 \mathrm{~Hz}$ in the overburden, $25 \mathrm{~Hz}$ in the Messinian evaporites, and $17 \mathrm{~Hz}$ in the sub-salt units. The seismic resolution, calculated as a quarter of the wavelength $(\lambda / 4$; Brown, 2011), varies according to lithology and depth below seabed, but is estimated to be c. $10 \mathrm{~m}$ in the clastic supra-salt overburden, c. $42 \mathrm{~m}$ in the Messinian salt interval and c. $44 \mathrm{~m}$ in the sub-salt, using average P-wave velocities of $2000 \mathrm{~m} / \mathrm{s}, 4200 \mathrm{~m} / \mathrm{s}$, and $3000 \mathrm{~m} / \mathrm{s}$ respectively (Gardosh and Druckman, 2006; Reiche et al., 2014; Feng et al., 2016). Where thicknesses and depths are measured and quoted in ms two-way-time (TWT), we use the average interval velocities to estimate the equivalent thickness in $\mathrm{m}$.

In order to analyse the development of RSBs we map reflections in the supra-salt stratigraphy, analyse their seismic-stratigraphic relationships, and generate structure and thickness (isopach) maps. Key horizons include base-salt, top-salt and seabed. The distribution of the salt and orientation of suprasalt faults and folds give context to the salt tectonic regime and basin evolution. We identify eight well-developed RSBs that have clearly defined onlap surfaces, and select 9 onlapping intra-RSB horizons (02-010; Fig. 2) that can be confidently correlated across the margin (spanning c. $100 \mathrm{~km}$ from NE to SW). Correlating seismic horizons between different RSBs allows us to compare the magnitude of translation along the margin during different time intervals, identifying lateral changes along strike. For the most part we discuss relative, rather than absolute, translation rates due the absence of accurate age constraints in the supra-salt strata. One key horizon is tentatively assigned an absolute age of 1.8 Ma based on a calibration with Kirkham et al. (2019) and Cartwright et al. (2018), who mapped this horizon northwards from wells in the southern Levantine Basin into their study areas. Should future data (i.e. from drilling) yield further meaningful age constraints within the suprasalt strata, this may be used to calculate absolute translation rates. Finally, we sum the heaves of saltdetached growth faults in the updip extensional domain to compare to the translation estimates given by the RSBs. Fault heave measurements are taken on seismic sections perpendicular to the dominant structural trend (i.e. parallel to the direction of extension).

We also generate variance and RMS amplitude attribute maps derived from the top-salt surface to identify and map fluid escape pipes (Barnes, 2016). Features related to subsurface fluid migration have been interpreted following the criteria described in literature (e.g. Cartwright and Santamarina, 2015). Variance maps highlight fluid escape features due their internally chaotic nature in comparison to the continuous reflections characterising the surrounding stratigraphy, whereas RMS amplitude maps show the anomalously low-amplitude regions where the otherwise high-amplitude, top-salt reflection has been disrupted by fluid escape. 
The seismic dataset used in this study is situated offshore Lebanon in the Levantine Basin. The Eastern Mediterranean comprises the Levantine and Herodotus Basins, separated by the Eratosthenes Seamount (Fig. 1). The Levantine Basin formed during Permo-Triassic and Jurassic multiphase rifting events (Nader et al., 2018) and contains up to $20 \mathrm{~km}$ of clastic material overlying thinned continental crust (Aal et al., 2000; Inati et al., 2016). The African plate collided with the Eurasian plate in the Late Cretaceous, initiating active subduction along the northern boundary of the basin. The complex collision geodynamics of the region led to additional phases of folding, thrusting, and sinistral strike-slip fault movements during the Late Miocene-Pliocene (Hall et al., 2005).

A thick (up to $2 \mathrm{~km}$ ), layered evaporitic sequence was deposited across the eastern Mediterranean during the Messinian Salinity Crisis (MSC) between 5.96 and 5.33 Ma (e.g. Gautier et al., 1994; Ryan, 2009; Roveri et al., 2014). During this time, the Mediterranean Sea was isolated from the Atlantic Ocean due to the closure of the Strait of Gibraltar, causing evaporitic drawdown and extensive salt precipitation. When the Strait of Gibraltar reopened in the Pliocene, marine Atlantic waters flooded the Mediterranean and a clastic overburden (up to $1.5 \mathrm{~km}$ thick) was deposited above the salt. Tectonically-driven tilting of the basin margins, as well as differential loading of the salt by prograding clastic wedges, triggered gravity-driven deformation of the Messinian salt (Gvirtzman et al., 2013; Allen et al., 2016). This resulted in the development of kinematically-linked zones of updip extension and downdip contraction (Fig. 1) (e.g. Jackson et al., 1994). The salt deformation is thought to be dominantly driven by gravity gliding in the northern Levantine Basin (due to tilting of the margin), whereas gravity spreading dominates in the south due to sediment load by the Nile deep-sea fan (Allen et al., 2016).

The present-day Eastern Mediterranean region remains tectonically active. The deformation front of the Cyprus Arc, dominated by the Latakia Ridge, forms the northern boundary of the Levantine Basin, where ongoing plate convergence maintains active subduction zones (Fig. 1) (Ben-Avraham, 1978; Hall et al., 2005). The western extension of the subduction zone forms an accretionary wedge, known as the Mediterranean Ridge, which bounds the Herodotus Basin to the north and west (Fig. 1). The Levant passive margin provides the eastern limit to the basin, offshore Lebanon and Israel (Hawie et al., 2013). N-S oriented strike-slip tectonics occur onshore adjacent to the margin along the Dead Sea Transform Zone, as the Arabian plate slides northwards past the African plate (Fig. 1). The north African passive margin forms the southern boundary to the basin, where the Nile river system is draining the African continental interior and supplying large quantities of clastic material to the rapidly prograding Nile Delta (Fig. 1). 


\subsection{Base-Salt Relief}

164

Salt flow is known to be sensitive to the geometry of the surface that it flows across (e.g. Dooley et al., 2017; Pichel et al., 2019; Evans and Jackson, 2019). Offshore Lebanon the base-salt surface dips generally to the NW, but with significant rugosity on this part of the Levant Margin (Fig. 3). The depth to base-salt shallows to the south of the dataset across the Saida Fault, a Mesozoic normal fault which bounds an elevated Mesozoic structural element known as the Saida-Tyr Platform (Fig. 3) (Ghalayini et al., 2018). The Latakia Ridge crosses the northwestern corner of the dataset and is expressed as a large, arcuate, broadly NE-trending anticline on both the base-salt and top-salt surfaces (Fig. 3 and Fig. 4b).

There are several, NE-trending anticlines distributed across the margin which vary from $100 \mathrm{~ms}$ up to $820 \mathrm{~ms}$ in height (c. $200 \mathrm{~m}$ up to $1.6 \mathrm{~km}$ respectively) (Fig. 3). In map view they are between 8 and 28 km long, and are typically 2-3 km wide (Fig. 3). Although the seismic data are presented in TWT, we know these anticlines are real geological structures and not seismic data artefacts (i.e. velocity pullup features) as the salt is thinner (as opposed to thicker) above the anticlines crest. Above one of the largest anticlines the salt thins to as little as $30 \mathrm{~ms}$ (c. $70 \mathrm{~m}$ ), from an adjacent thickness of $500 \mathrm{~ms}$ (c. $1.3 \mathrm{~km}$ ) (Fig. 2). These anticlines are thought to have developed during the Late Miocene due to the NW-SE oriented regional tectonic compression associated with continental convergence, and may be fault-propagation folds overlying deeper thrust faults (Ghalayini et al., 2014; Ghalayini et al., 2018). Several of the folds were formed during transpressional reactivation of the Saida Fault (Fig. 3). They therefore predate deposition of the Messinian salt (Hawie et al., 2013), although it is possible that there may have been some later amplification of these structures in response to ongoing compression (Ghalayini et al. 2014).

We also note the base-salt is offset by evenly-spaced, NW-SE striking, short (up to $6 \mathrm{~km}$ ), lowdisplacement (30-60 ms TWT; c. 50-90 m) normal faults that are particularly common in the deeper basin (Fig. 3). In cross section these appear to be layer-bound, sub-salt normal faults terminating at the base-salt, and that do not extend upwards into the overlying salt. These have been interpreted as Late Miocene syn-sedimentary faults that formed in response to an anisotropic stress field (Ghalayini et al. 2017; Reiche et al, 2014).

\subsection{Salt Distribution and Supra-Salt Structure}

The Messinian salt layer overall thickens westward into the deep Levantine Basin and thins updip, pinching out onto the Levant Margin (Fig. 4a). The evaporite sequence is lithologically heterogeneous, 
leading to internal seismic reflectivity within the deforming salt sheet (e.g. Fig. 5) (Gvirtzman et al., 2013; Feng et al., 2016; Meilijson et al., 2019; Evans and Jackson, 2020). The intrasalt reflections are folded and faulted, and are truncated landward against the top-salt due to an earlier, syn-depositional phase of deformation, erosion, and dissolution (Gvirtzman et al., 2013; Gvirtzman et al., 2017; Feng et al., 2017; Kartveit et al., 2018; Kirkham et al., 2020; Evans and Jackson, 2020).

The supra-salt structure of the basin can be divided into kinematically-linked domains of updip extension and downdip contraction, separated by a relatively undeformed translational domain (Fig. 1). The present dataset mostly covers the extensional and upper translational domains, with minimal contraction in the overburden, except where the Latakia Ridge locally restricts salt flow in the north, resulting in the formation of NE-trending buckle folds (Fig. 4b; Evans and Jackson, 2020). The extensional domain is dominated by salt-detached normal faults and associated salt rollers striking sub-parallel to the margin, perpendicular to the base-salt dip (Fig. $4 \mathrm{~b}$ and 5 ). The trend of these structures is entirely consistent with a dominant NW direction of translation driven by gravity gliding (Evans and Jackson, 2020). The dominant strike of the supra-salt faults rotates toward the south, from NNE to ENE, closely following the geometry of the base-salt surface and orientation of the salt pinchout (Fig. 4b). A small region towards the north of the dataset is dominated by a polygonal network of mature reactive diapirs (Fig. 4b).

\subsection{Ramp Syncline Basins}

The NE-trending sub-salt anticlines are associated with supra-salt RSBs positioned above and adjacent to their basinward flanks, recording the progressive basinward translation of the salt and overburden over the anticlines. They can be easily recognised in cross section by their characteristic landwarddipping, asymmetric growth strata (Fig. 2). The growth strata packages thicken toward, and terminate against, the basal RSB 'onlap surface'. The onlap surface is diachronous, cutting up through the stratigraphy and younging toward the anticline. It typically has a listric geometry in cross section, being steepest at the youngest stratigraphic level and flattening with depth and distance from the anticline (Fig. 2). The listric geometry causes the onlapping intra-RSB horizons to rotate downward as they are translated away from the anticline, thus forming pseudo-downlaps (Fig. 2). The thickness of sediment beneath the RSB (i.e. between the onlap surface and the top-salt) also increases toward the anticline, reflecting the amount of sediment accumulated updip prior to basinward translation into the RSB depocentre. These observations are all consistent with RSB geometries generated by numerical models of overburden translation over base-salt steps (see Pichel et al., 2018). across-strike spacing of only c. $10 \mathrm{~km}$ (Fig. 6). The dual development of the two RSBs means that strata 
in the basinward RSB onlaps strata in the landward RSB, such that the two basins may become vertically juxtaposed with continued translation (forming stacked RSBs; see Pichel et al., 2018).

Small base-salt anticlines (c. $100 \mathrm{~ms}$ ) are associated with poorly-developed RSBs whose onlap surface is difficult to trace, and that show only very subtle landward expansion of growth strata. This is attributed to the small amplitude of the anticline relative to the total salt thickness, which means that the associated depocentre is relatively small (Pichel et al., 2018). We also observe partially-formed RSBs within the extensional domain, disrupted by normal faults (Fig. 7). These appear to represent a kinematic system whereby basinward translation of undeformed overburden is intermittently interrupted by slip on normal faults, causing RSB development to 'switch on and off' (Fig. 7). This observation shows that RSB development is not limited to the translational domain, as suggested by previous studies, but can occur anywhere on the margin where salt translates over base-salt relief. However, RSBs developing in extensional settings are more likely to be disrupted by normal faulting and associated salt rollers. Such structures likely preferentially nucleate over the crest of the anticlines where there is a salt flux imbalance (Dooley et al., 2017), thus disrupting the continuous basinward translation that is required to maintain the RSB depocentre.

In this study we identify and map in 3D the internal stratigraphy of eight well-developed RSBs (Fig. $8 \mathrm{e})$, whose onlap surface is clearly defined and which thus provide a reliable record of continuous basinward translation. Onlaps can be observed adjacent to the anticline at the present-day sea floor, where the RSB 'hinge' is typically represented by a bathymetric low, indicating ongoing RSB development and basinward translation (e.g. Fig. 2). The onlap surface does not, however, reach down to the top-salt, instead terminating against a thin (average $170 \mathrm{~ms}$ or c. $170 \mathrm{~m}$ ), largely isopachous (but overall basinward-thinning) supra-salt unit. This is interpreted as a pre-kinematic layer (deposited prior to initiation of RSB development). The oldest intra-RSB strata therefore directly onlap onto the pre-kinematic unit (e.g. Fig. 2).

We map selected intra-RSB horizons that can be traced confidently across the margin (O2-O10; Fig. 2). Intra-RSB units show elongate depocentres with maximum thickness in the centre of the RSB, and a corresponding onlap sub-parallel to the origin anticline (Fig. 8a). Similarly, onlap surfaces show the greatest depression in the centre of the RSB, adjacent to the maximum height of the anticline (Fig. 8b). Intra-RSB units show the migration of depocentres away from the anticline with increasing age (Fig. 8c) (see also Pichel et al., 2018 and Pichel et al., 2019). The intra-RSB depocentres may be used to determine the direction of salt flow by tracing the position of the thickest part of the depocentre through time (Fig. 8c). In older, more deeply buried basins, the precision of this technique may be limited by later faulting, diapirism, and other tectonic processes that subsequently deform the intra- 
RSB isopachs. However, the original geometries of the young RSBs on the Levant Margin are exceptionally well-preserved. The present-day RSB hinges and the intra-RSB onlaps have a linear or curvilinear expression in map-view, trending parallel or sub-parallel to the anticline from which they originate (Fig. 8d). The length of the onlaps (and of the corresponding RSB depocentre) is determined by the length of the adjacent anticline (Fig. 8e).

265

266

267

268

269

270

271

\subsection{Fluid Escape Pipes}

Several of the RSBs are cross-cut by vertical features that have an internally chaotic or transparent seismic expression (Fig. 2, Fig. 5 and Fig. 6). They extend vertically between the top-salt and the diachronous RSB onlap surface, commonly being capped by a pockmark. In map view they form linear trails and are interpreted as series of fluid escape pipes (Fig. 9) (Cartwright et al., 2018; Kirkham et al., 2019; Oppo et al., 2020). As well as the vertical pipes preserved within the overburden, we can also identify the arcuate traces of the deformed pipes preserved within the salt sheet itself, connecting the base of the pipe at the top-salt to its origin in the sub-salt anticline (Fig. 6). The pipes invariably root to the crest or the downdip flank of the anticlines, indicating a sub-salt origin for the escaped fluids, with the anticlines acting as traps and the salt as an imperfect seal (Al-Balushi et al., 2016; Cartwright et al., 2018; Oppo et al., 2020).

We identify twelve pipe trails in the dataset, all of which originate from sub-salt anticlines that also generate RSBs (Fig. 8e). The pipe trails record the progressive basinward translation of the overburden due to their transient nature (Cartwright et al., 2018): each pipe forms vertically above the crest of the anticline, releasing pressure accumulated in the sub-salt trap in a single event, before being passively translated basinward into the RSB depocentre where they become buried (Fig. 10). As it is translated into the RSB depocentre, the pockmark is onlapped by the RSB growth strata (Fig. 10). Critically, this means that the age of each pipe is approximately equivalent to the age of the horizon that meets the pockmark at the onlap surface (Fig. 10). All pipes are thought to be inactive fluid pathways once they are translated away from the crest of the anticline. The sub-salt trap then recharges until it once again exceeds the critical pressure required for the fluids to hydro-fracture the overlying salt and generate a new fluid escape pipe (Fig. 10) (Cartwright et al., 2018; Oppo et al., 2020).

Pipe trails can therefore be used to determine the direction of translation by tracking a single point through time (Fig. 9). Some trails form a well-defined linear trend, whereas others show significantly more scatter, indicating that the precise emission point may vary slightly through time (Fig. 8d). They can be treated as direct kinematic vectors of transport direction at different localities along the margin, with the intra-RSB horizons constraining the relative ages of the pipes between different, widely spaced RSBs (Fig. 8d). All pipe trails identified in the present study trend broadly NW, indicating 
a NW direction of translation, which is consistent with the orientation of supra-salt faults updip. They do, however, show some variation in the precise direction of translation along margin, rotating from a more NNW bearing in the northern part of the dataset $\left(295^{\circ}\right)$ to a more WNW bearing in the south $\left(335^{\circ}\right)$. This rotation in transport direction is consistent with the observed change in the strike of faults in the updip extensional domain (Evans and Jackson, 2020).

The deformed pipes provide a unique means to examine the internal flow dynamics of a deforming salt sheet, whereas in the past much of our understanding has had to rely on numerical and physical analogue models, with few ways of constraining the natural systems themselves (e.g. Davison et al., 1996; Albertz and Ings, 2012). We observe arcuate pipe geometries that flatten with depth and are largely consistent with those of the previous studies (Cartwright et al., 2018; Kirkham et al., 2019), where the authors use the inclined nature of the deformed pipes to infer a dominant Couette (i.e. drag-induced) flow profile within the salt sheet.

\subsection{Kinematic Analysis}

306

Integrating the information given by the RSBs and fluid escape pipes, we can analyse lateral variations in the magnitude and direction of translation recorded at different localities along the northern Levantine Basin margin. The intra-RSB onlaps give the magnitude of translation and some indication of the direction, but since their orientation is most sensitive to the orientation of the anticline from which they originate, they may be oblique to the actual direction of translation shown by the pipes (e.g. RSB 8 in Fig. 8e). The translation direction is therefore more precisely constrained by either the orientation of the pipe trails or the migration of the RSB depocentres (Fig. 8c-d).

The first onlap onto the pre-kinematic layer at the base of the RSB records the initiation of RSB development, and therefore the onset of salt-detached gravity gliding of the overburden ( $\mathrm{O} 10 \mathrm{in} \mathrm{Fig.}$ 2). Note that this constitutes the second main phase of salt deformation, with an earlier phase of syndepositional deformation occurring prior to overburden deposition (Gvirtzman et al., 2013; Gvirtzman et al., 2017; Feng et al., 2017; Kartveit et al., 2018; Kirkham et al., 2020; Evans and Jackson, 2020). The age of this first onlap appears to be the same (or within two reflections) for all of the RSBs mapped in this study, meaning that the onset of gravity gliding was broadly synchronous across the margin. This horizon also appears to correspond to the $1.8 \mathrm{Ma}$ age horizon indicated by Kirkham et al. (2019) (based on a correlation with well data from the southern Levantine Basin, offshore Israel).

Given that each onlap originally formed at the RSB hinge before being buried and translated basinward, the total translation is given by the horizontal distance from the first onlap to the present RSB hinge (Fig. 2). This method assumes that the position of the RSB hinge has been stable through 
time, which we believe to be a valid assumption based on the results of numerical analogue models (Pichel et al. 2018).

The total amount of translation for each RSB varies between 5 and $7 \mathrm{~km}$ (Onlap 10 in Fig. 11a). This represents a scatter of up to $17 \%$ about the mean of $6 \mathrm{~km}$, with an average absolute deviation of 0.6 $\mathrm{km}$. There does not appear to be a systematic spatial trend from north to south along the margin (i.e. increasing or decreasing magnitudes of translation from north to south), but there is evidently some lateral variability in the average rate of overburden translation (from c. $2.8 \mathrm{~mm} / \mathrm{yr}$ up to $3.9 \mathrm{~mm} / \mathrm{yr}$, assuming that the $1.8 \mathrm{Ma}$ horizon represents the onset of gravity gliding). RSB 6 has the largest magnitude of translation $(7 \mathrm{~km}$ ) and is located $60 \mathrm{~km}$ from RSB 2, which has the smallest magnitude of translation $(5 \mathrm{~km})$. We do not identify any discrete strike-slip faults accommodating these differential rates within the overburden. This means that the rigid overburden has accommodated a very modest shear strain of c. $0.03(2 \mathrm{~km} / 60 \mathrm{~km})$, with an angular shear of $2^{\circ}$.

The basinward translation of RSBs is accommodated updip by a network of salt-detached normal faults (Fig. $4 \mathrm{~b}$ and Fig. 5). Summing the horizontal components of slip (i.e. heave) of faults in the extensional domain gives a horizontal translation estimate that we can compare to the RSB-derived estimates of total translation (Fig. 12). This method yields extension values of 4.7-7.0 km, which are largely consistent with translation estimates from the RSBs (Fig. 12). Profile 1 sums to $7.0 \mathrm{~km}$ of horizontal displacement, which is consistent with the $7.0 \mathrm{~km}$ of translation recorded by RSB 6 downdip. Profiles 3, 4 and 5 give 6.1-6.6 km of horizontal displacement, which is consistent with the 6.7 and $6.3 \mathrm{~km}$ of translation recorded by RSB 4 and RSB 5, respectively. Conversely, the horizontal displacement estimate derived from Profile $2(5.5 \mathrm{~km})$ is significantly less than that recorded by RSB 6 downdip $(7.0$ $\mathrm{km})$, likely due to missing strain accommodated by sub-seismic scale faults. Overall, translation estimates from fault heaves support the apparent lateral variability in translation rates along the margin derived from the RSBs (Fig. 12). Note that we cannot measure fault heaves updip of RSBs 1, 2 or 3 due to the domain of diapiric growth, or for RSBs 7 and 8 due to the southern limit of the dataset (Fig. 12).

As well as total translation estimates, we can compare the translation magnitudes for other intra-RSB horizons of equivalent ages (Fig. 11a), and use these to calculate the incremental translation during different time intervals (Fig. 11b). For example, the distance between Onlap 10 and Onlap 9 gives the distance that each RSB moved during that interval of time (Fig. 11b). We can therefore use this to compare the relative translation rates of the RSBs through time. This approach assumes that the correlated intra-RSB horizons represent temporally equivalent surfaces across the margin, which we believe to be valid based on the lack of seismic-scale unconformities in the overburden and apparently 
continuous sediment aggradation since the Messinian (e.g. Fig. 5). These incremental translations show significantly more variability between different RSBs than the total translations, with some time intervals showing a scatter of up to $80 \%$ about their average (e.g. 06-05 gives values within a the range 100-900 m with an average of $500 \mathrm{~m}$ ) (Fig. 11b). Furthermore, we see that the relative velocity of each RSB varies through time (i.e. the fastest and slowest RSBs on average, RSB 6 and RSB 2 respectively, have not been consistently fastest or slowest through time) (Fig. 11b). For example, the incremental translations show that the relatively large magnitude of translation recorded by RSB 8 is primarily due to a very recent episode of increased velocity that was not experienced by the other RSBs. In fact, all RSBs appear to experience 'pulses' of faster translation rates punctuated by periods of slower translation rates, such that the seemingly random variability observed on short (c. 100-200 Kyr) timescales averages out over longer (c. 1-2 Myr) timescales. After one RSB experiences a faster 'pulse', it then slows relative to the others, such that all RSBs 'keep-up' with each other to a certain degree over long enough timescales. This means that the average translation rate would eventually converge to a common value for all RSBs along the margin given a long enough time period.

\section{Discussion}

The young and active RSBs offshore Lebanon provide an excellent stratigraphic record of the magnitude and timing of salt-detached gravity gliding. As the rigid overburden slides on the ductile salt layer, the RSB depocentres and onlapping strata are progressively transported downdip from the adjacent causal anticline, allowing us to quantify the incremental basinward translation through time. The direction of translation is constrained by tracing the RSB depocentres through time, or by using the orientation of fluid escape pipe trails, which track a single point through time and thus give a direct kinematic vector.

The temporal correlation of the oldest onlap surface between the RSBs suggests that they developed at approximately the same time, and therefore that the onset of gravity gliding was broadly synchronous across the entire margin (c. $1.8 \mathrm{Ma}$ ). This roughly coincides with the age of the oldest fluid escape pipes in the region, though not all pipe trails initiated at this time (see also Oppo et al., 2020). Therefore, the initiation of gravity gliding and fluid escape is broadly contemporaneous across the entire northern Levantine Basin, suggesting a single trigger for both events. The most recent phase of uplift of the Levantine margin was recorded by a change in drainage direction in northern Israel starting at c. 1.8 Ma (Matmon et al., 1999). This uplift could have increased the tilt of the base-salt enough to generate gravitational instability and initiate post-Messinian gravity gliding. At the same time, the basin tilt would have also favoured updip fluid (e.g. oil and gas) migration from the deep 
basin towards the anticlines along the basin margin (Oppo et al., 2020). The combination of updip fluid migration filling the sub-salt traps, and the exsolution of gas from oil due to a decrease in pressure, could together have led to supra-lithostatic overpressure within the anticlines, thus triggering crossevaporite fluid escape (Oppo et al., 2020).

The original study to identify a pipe trail associated with an anticline in the deep Levantine Basin (termed the Oceanus structure) used the horizontal distance from the oldest pipe to the present emission point to estimate the magnitude of translation $(3.4 \mathrm{~km}$ ) (Cartwright et al., 2018). Assuming this to be the total translation since deposition of the 1.8 Ma marker horizon, the authors calculate an average translation rate of $2.0 \mathrm{~mm} / \mathrm{yr}$. However, the RSBs onlaps show that translation actually initiated prior to the emission of the first pipe, and that the distance from the first onlap onto the 1.8 Ma horizon to the present-day RSB hinge in fact suggests $4.6 \mathrm{~km}$ of translation in this time (see Fig. $2 \mathrm{~b}$ in Cartwright et al., 2018). This yields a faster translation rate of $2.7 \mathrm{~mm} / \mathrm{yr}$ (i.e. 35\% higher than that estimated from the pipes alone). The RSB onlaps also show that the overburden has thickened through time, from a thin (c. $120 \mathrm{~m}$ ) pre-kinematic layer at $1.8 \mathrm{Ma}$ to the present-day thickness (c. $400 \mathrm{~m}$ ). This means that the stress acting on the salt has increased through time and it is therefore more accurate to use a time-averaged overburden thickness than present-day overburden thickness when calculating viscosity (ratio of shear stress to shear strain rate; see supplementary info in Cartwright et al., 2018). However, the recalculated viscosity $\left(1.1 \times 10^{18} \mathrm{~Pa}\right.$ s) using the newly constrained translation rate $(2.7$ $\mathrm{mm} / \mathrm{yr}$ ) and time-averaged overburden thickness (260 m assuming constant sedimentation rate) is of the same order of magnitude as that estimated by the previous study $\left(2.3 \times 10^{18} \mathrm{~Pa} \mathrm{~s}\right.$; Cartwright et al., 2018). Both values fall within the expected viscosity range derived from other natural examples and from laboratory experiments of rock salt rheology (Urai and Spiers, 2007; Urai et al., 2008; Mukherjee et al., 2010).

Another previous study investigated four closely spaced pipe trails within RSB 8, associated with the southernmost anticline in the present dataset (Saida-Tyr structure; Fig. 3) (Kirkham et al., 2019). The authors postulate the presence of 'streams' of fast-flowing salt based on the assumption that the first pipe in each trail formed at the same time (Fig. 13). However, using the intra-RSB onlaps to constrain the relative ages of the first pipes, which are not in fact the same age, we show that c. $1.5 \mathrm{~km}$ of translation had actually occurred between the formation of the oldest pipe in trail STP 1 and the oldest pipein trail STP 3 (Fig. 13). This observation does not support large differences in salt flow velocity across a single RSB and questions the presence of fast-flowing salt streams. In fact, the sub-parallel intra-RSB onlaps mapped show that local rates of basinward translation are approximately uniform over individual km-scale anticlines (i.e. we do not see any major rotation or deformation of onlaps as they are translated away from the anticline; Fig. 13). 
However, our correlation of horizons between different RSBs along the margin shows that both the direction and rate of translation do vary significantly through space and time over a larger spatial scale. This leads us to discuss two possible mechanisms that may be controlling this lateral variability in translation rate along the margin.

\subsection{Salt Flux Imbalance and Cyclical 'Pulses' of Flow}

Thinning of the salt over the crests of the anticlines leads to an imbalance in salt flux. On the updip flank of the anticlines there is a large volume of salt forced to squeeze through a relatively small gap between the sub-salt anticline and relatively strong clastic overburden. Physical analogue models show that salt flux imbalances such as this can cause temporal variations in salt (and overburden) velocity (Dooley et al., 2017). A simple experiment modelling salt flow up onto a base-salt high shows that during the early stages of deformation, the salt slows down and inflates as flow lines converge (see Fig. 18 in Dooley et al., 2017). Subsequently, as the salt above the high thickens, the effects of basal drag are minimised and the salt accelerates. Some anticlines in the present study show evidence of inflation on the updip flank of subsalt anticlines (e.g. Fig. 2), and we therefore propose a similar mechanism may play a role in modulating local rates of salt and overburden translation here (Fig. 14). In the first instance, pressure builds within the salt on the updip flank due to the volumetric mismatch (more salt input than output) (Fig. 14a). This may also be associated with inflation, though the confining pressure from the overburden weight resists this. On the downdip flank the flux imbalance causes the salt to thin and overburden to subside (more salt output than input), creating the RSB depocentre adjacent to the anticline. This process gradually increases the pressure difference $(\Delta \mathrm{P})$ across the anticline (Fig 14a T0-T1). In turn, this pressure difference increases the stress acting upon the salt, and since stress is proportional to strain rate, the velocity of salt flow across the anticline increases (Fig 14a, T0-T1). The premise that stress is proportional to strain rate applies to Newtonian fluids, which is a valid approximation in this case where the stress is relatively low and pressure solution is the dominant mechanism of salt flow (Spiers et al., 1990; Van Kekan et al., 1993; Urai et al., 2008). The acceleration of the salt flow is proportional to the pressure difference across the anticline, such that maximum acceleration occurs when $\Delta P$ is at its peak (Fig. 14a, T1). This velocity increase reduces the volumetric imbalance across the anticline and allows the pressure difference to drop (Fig. $14 a, T 1-T 2)$. As the system approaches equilibrium, the stress acting on the salt is reduced and it begins to decelerate (Fig. 14a, T2-T3). The pressure difference across the anticline then starts to build up again, and the process repeats (Fig 14a, T3-T4). This mechanism would allow for cyclical 'pulses' of faster salt flow (and overburden translation) during certain time intervals. The timing of the salt 'pulses' would vary for different anticlines depending on the thickness of the salt over the anticline, the adjacent salt thickness updip, and the thickness of the overburden, amongst other variables. 
The anticlines associated with the RSBs in this study have maximum heights between $220-820 \mathrm{~ms}$ (430 $\mathrm{m}$ up to $1.6 \mathrm{~km}$ ). The thickness of salt over the anticlines tends to be inversely proportional to their height, with larger anticlines generally capped by thinner salt over their crests (Fig. 15a). The difference between the adjacent thickness of salt updip, and the thickness of salt over the crest, can be used as a proxy for salt flux imbalance (Fig. 15a). This means that we would expect anticlines with a large thickness of adjacent salt and very thin salt over their crest to have a large salt flux imbalance. Some anticlines are therefore associated with larger salt flux imbalances than others (Fig. 15a).

This observation and inference could explain why some RSBs demonstrate more extreme 'pulses' of salt flow than others (Fig. 11b). In order to evaluate this variability quantitatively, we calculate the average absolute deviation for each RSB, and find that this is proportional to the salt flux imbalance with an $\mathrm{R}^{2}$ value of 0.9 (Fig. 15b). This means that RSBs with a greater salt flux imbalance deviate more from the average magnitude of translation at each time step (Fig. 15b). We suggest that this is because where the volumetric imbalance is relatively small (i.e. salt thickness is more uniform across the anticline), pressure differences are released more easily (Fig. 14b). Consequently, the 'pulses' of faster and slower translation are less extreme, and translation rates are generally more consistent over time (Fig. 14b). This is the case for RSBs 4 and 5 (Fig. 15b). Conversely, the anticlines with the greatest flux imbalance show more extreme variability because they must build up a greater pressure difference in order to equilibrate over the anticline (Fig. 14a). This is the case for RSBs 2, 3 and 8 (Fig. 15b). We note that there may have been some post-Messinian amplification of these anticlines absorbed by salt thinning, which would further augment the salt flux imbalance over time, but the lack of stratigraphic evidence for overburden uplift suggests that this would have been relatively minor.

This mechanism could also explain why even the dual RSBs (2 and 3) show slightly different rates of translation (Fig. 11). The anticlines associated with RSB 2 and RSB 3 are $10 \mathrm{~km}$ apart and parallel to one another (Fig. 6 and Fig. 8e). They record translation on the same part of the margin, but show slightly different magnitudes of total translation. It appears that the landward RSB has translated further than the basinward RSB (5.3 km and $4.9 \mathrm{~km}$ respectively), as well as experiencing slightly different magnitudes of incremental translation through time (Fig. 11b). The anticlinal geometry of the landward intra-RSB strata could suggest that the additional $400 \mathrm{~m}$ of translation may have been accommodated via large-scale folding, as well as possible cryptic lateral compaction (Fig. 6) (e.g. Butler and Paton, 2010).

While salt flux imbalances may play a key role in modulating local rates of translation over base-salt anticlines, there are other key controls that we also need to consider. The Couette flow profile inferred from the geometry of the deformed pipes indicates that drag on the top-salt surface is the dominant 
driver of salt deformation in this area (Cartwright et al., 2017; Kirkham et al., 2019). This means that it is the translation of the overburden that drives salt deformation, and not vice versa. We must therefore consider mechanisms that facilitate the basinward translation of the overburden, and their key controls, in order to fully understand the differential rates of overburden translation.

\subsection{Overburden Mechanics and Elastic Strain}

An alternative or additional mechanism that could be controlling translation rates of the salt and its overburden is the distribution of elastic stress and strain in the relatively rigid overburden. If we treat the overburden as a uniform sheet (Fig. 16a) and apply a tilt (Fig. 16b), the gravitational force acting on the tilted overburden, and therefore the tectonic stress, is approximately constant along the margin but increases updip (where the weight of the downdip sheet is greatest). This causes elastic strain to build up within the overburden, which is proportional to the applied stress and therefore also increases updip (Fig. 16b). When the stress exceeds the strength of the overburden, brittle failure occurs and faults develop (Fig. 16c-f). The development and growth of these faults thus facilitates the basinward translation of the overburden (Fig. 5).

However, the extent to which these faults control the rate of translation in the translational domain downdip is unclear, and depends largely on whether the mechanical behaviour of the overburden is dominantly plastic or dominantly elastic. In a dominantly plastic deformation model, where materials deform at constant stress, the translational domain is permitted to pull away at a uniform rate, with faults updip locally releasing the elastic strain when brittle failure occurs (Fig 16c-d). In a dominantly elastic deformation model, where strain is directly proportional to stress, the tension in the sheet is maintained and the faults updip allow the sheet downdip to pull forward by a magnitude dictated by the fault heave (Fig. 16e-f). In reality, the mechanical behaviour of the overburden at the margin scale is elasto-plastic (Weijermars et al., 1993) and therefore the actual overburden deformation is a hybrid of these two end-member models. In either case, this means that the rate of basinward translation in the extensional and upper translational domains, where the majority of RSBs are located, is intrinsically linked to the slip rate on the faults (Fig. 16). These faults move at different times, due to a number of independent variables in the system (rheological heterogeneity, geometry of the fault plane, fluid circulation, etc.) that make it very difficult to predict when or in which order the different fault segments will slip. This phenomenon is well-documented on fault networks in areas of active extension, with many studies showing that fault activity is inherently episodic and that slip rates vary through time and space (e.g. Mitchell et al. 2001; Benedetti et al. 2002; Friedrich et al. 2003; Bull et al. 2006; Nicol et al. 2006; McClymont et al. 2009; Schlagenhauf et al. 2010, 2011; Cowie et al., 2012). This may explain some of the seemingly random variability in rates of translation along the margin. Note that this simplified model considers only the mechanics of the updip extensional and 
525 translational domains, and further complexity may be introduced by incorporating stresses within the 526 contractional domain downdip. Nevertheless, this gives valuable insights into some key controls in the 527 updip region where the RSBs are situated.

528 Furthermore, these faults transfer elastic strain and stress between different segments of the 529 overburden during each slip event (e.g. Cowie 1998; Robinson et al. 2009; Cowie et al., 2012). If one 530 part of the relatively rigid overburden sheet is moving faster than the adjacent segment, as the RSBs 531 have shown, this difference would have to be accommodated by a discrete NW-trending strike-slip 532 fault, or distributed over a wider zone and stored as shear strain. Strike-slips faults are observed in the 533 overburden offshore Israel where they offset subaqueous channels (Cartwright et al., 2012; Clark and 534 Cartwright, 2009; Kartveit et al., 2018), and likely accommodate differential rates of salt-detached 535 translation between different segments of the margin. However, we do not identify similar salt536 detached strike-slip faults in the overburden offshore Lebanon, and therefore infer that the 537 differential translation must be accommodated by distributed elastic shear strain. Since the 538 overburden is a relatively rigid sheet, it can only accommodate a certain amount of elastic strain 539 without brittle failure. This means that when one fault ruptures and a segment moves locally, this 540 increases the elastic strain in neighbouring segments, thus bringing them closer to failure (Fig. 16c-d). 541 This strain is then released when the neighbouring segments slip and 'catch up' with the first segment 542 (Fig. 16e-f). We therefore envisage that the distribution of stress and storage of elastic strain in the 543 overburden could explain the fact that all segments appear to 'keep-up' with each other over long 544 timescales.

545 Essentially, this demonstrates that over margin-scale lengths the overburden undergoes a process of 546 tectonic 'stretching and squeezing' as it translates basinward, rather than uniformly translating as a 547 perfectly rigid material. Since the overburden in the Levantine Basin is relatively young and shallowly 548 buried, it may be able to accommodate more elastic strain than thicker, more compacted and 549 consolidated clastic overburdens in other basins (Butler and Paton, 2010; Burberry, 2015). We 550 conclude that the interplay between the cyclical 'pulsing' of salt flow over base-salt anticlines and the 551 mechanical behaviour of the overburden control differential rates of basinward translation on the 552 Levant Margin, and similar processes are expected to occur in other salt basins. 


\section{Conclusions}

564

565
- The well-developed ramp syncline basins offshore Lebanon are excellent records of translation on a salt-influenced passive margin dominated by gravity-gliding

- Pipe trails provide direct vectors of transport direction, and the relative ages of the pipes can be determined by correlating intra-RSB horizons across the margin

- Rates of basinward translation are approximately uniform at the $\mathrm{km}$-scale but show significant lateral variability at the margin-scale

- Differential translation rates may be a result of pulsed salt flow due to volumetric imbalance over the base-salt anticlines

- The overburden deforms as it translates, with the distribution of stress and elastic strain ensuring that translation rates average out over long timescales

\section{Acknowledgements}

The authors would like to thank Tim Dooley, Frank Peel and other members of Applied Geodynamics Laboratory at UT Austin for valuable discussions that helped to shape our interpretations. We also gratefully acknowledge Ramadan Ghalayini, Wissam Chbat and the Lebanese Petroleum Administration for the provision of data without which this project would not have been possible. Seismic interpretation was facilitated by Schlumberger's Petrel software, provided on an academic license. 
572 Aal, A.A., El Barkooky, A., Gerrits, M., Meyer, H., Schwander, M. and Zaki, H., 2000. Tectonic evolution

573 of the Eastern Mediterranean Basin and its significance for hydrocarbon prospectivity in the 574 ultradeepwater of the Nile Delta. The Leading Edge, 19(10), pp.1086-1102.

575 Al-Balushi, A.N., Neumaier, M., Fraser, A.J. and Jackson, C.A., 2016. The impact of the Messinian 576 salinity crisis on the petroleum system of the Eastern Mediterranean: a critical assessment using 2D 577 petroleum system modelling. Petroleum Geoscience, 22(4), pp.357-379.

578 Albertz, M. and Ings, S.J., 2012. Some consequences of mechanical stratification in basin-scale 579 numerical models of passive-margin salt tectonics. Geological Society, London, Special Publications, 580 363(1), pp.303-330.

581 Allen, H., C.A.-L. Jackson and A.J. Fraser, 2016, Gravity-driven deformation of a youthful saline giant: 582 the interplay between gliding and spreading in the Messinian basins of the Eastern Mediterranean: 583 Petroleum Geoscience, v. 22, p. 340-356.

584 Barnes, A., 2016. Handbook of Poststack Seismic Attributes. Society of Exploration Geophysicists.

585 Ben-Avraham, Z., 1978. The structure and tectonic setting of the Levant continental margin, eastern 586 Mediterranean. Tectonophysics, 46(3-4), pp.313-331.

587 Benedetti, L., Finkel, R., Papanastassiou, D., King, G., Armijo, R., Ryerson, F., Farber, D. \& Flerit, F., 588 2002. Post-glacial slip history of the Sparta fault (Greece) determined by $36 \mathrm{Cl}$ cosmogenic dating: 589 evidence for non-periodic earthquakes, Geophys. Res. Lett., 29, 1246, doi:10.1029/2001GL014510.

590 Brown, A.R., 2011. Interpretation of three-dimensional seismic data. Society of Exploration 591 Geophysicists and American Association of Petroleum Geologists.

592 Brun, J.P. and Fort, X., 2011. Salt tectonics at passive margins: Geology versus models. Marine and 593 Petroleum Geology, 28(6), pp.1123-1145.

594 Bull, J.M., Barnes, P.M., Lamarche, G., Sanderson, D.J. Cowie, P.A., Taylor S.K. \& Dix, J.K., 2006. High595 resolution record of displacement accumulation on an active normal fault: implications for models of 596 slip accumulation during repeated earthquakes, J. Struct. Geol., 28, 1146-1166.

597 Burberry, C.M., 2015. Spatial and temporal variation in penetrative strain during compression: Insights 598 from analog models. Lithosphere, 7(6), pp.611-624.

599 Butler, R.W.H. and Paton, D.A., 2010. Evaluating lateral compaction in deepwater fold and thrust belts: 600 How much are we missing from "nature's sandbox". GSA Today, 20(3), pp.4-10.

601 Cartwright, J., Kirkham, C., Bertoni, C., Hodgson, N. and Rodriguez, K., 2018. Direct calibration of salt 602 sheet kinematics during gravity-driven deformation. Geology, 46(7), pp.623-626.

603 Cartwright, J. and Santamarina, C., 2015. Seismic characteristics of fluid escape pipes in sedimentary 604 basins: implications for pipe genesis. Marine and Petroleum Geology, 65, pp.126-140.

605 Cartwright, J., Jackson, M., Dooley, T. and Higgins, S., 2012. Strain partitioning in gravity-driven 606 shortening of a thick, multilayered evaporite sequence. Geological Society, London, Special 607 Publications, 363(1), pp.449-470. 
608

609

610

611

612

613

614

615

616

617

618

619

620

621

622

623

624

625

626

627

628

629

630

631

632

633

634

635

636

637

638

639

640

641

642

643

644

645

Cartwright, J.A. and Jackson, M.P.A., 2008. Initiation of gravitational collapse of an evaporite basin margin: The Messinian saline giant, Levant Basin, eastern Mediterranean. Geological Society of America Bulletin, 120(3-4), pp.399-413.

Clark, I.R. and Cartwright, J.A., 2009. Interactions between submarine channel systems and deformation in deepwater fold belts: Examples from the Levant Basin, Eastern Mediterranean sea. Marine and Petroleum Geology, 26(8), pp.1465-1482.

Coleman, A.J., Jackson, C.A.L. and Duffy, O.B., 2017. Balancing sub-and supra-salt strain in saltinfluenced rifts: Implications for extension estimates. Journal of Structural Geology, 102, pp.208-225.

Cowie, P.A., 1998. A healing-reloading feedback control on the growth rate of seismogenic faults, J. Struct. Geol., 20, 1075-1087.

Cowie, P.A., Roberts, G.P., Bull, J.M. and Visini, F., 2012. Relationships between fault geometry, slip rate variability and earthquake recurrence in extensional settings. Geophysical Journal International, 189(1), pp.143-160.

Davison, I., Alsop, I. and Blundell, D., 1996. Salt tectonics: some aspects of deformation mechanics. Geological Society, London, Special Publications, 100(1), pp.1-10.

Dooley, T.P., Hudec, M.R., Carruthers, D., Jackson, M.P. and Luo, G., 2017. The effects of base-salt relief on salt flow and suprasalt deformation patterns-Part 1: Flow across simple steps in the base of salt. Interpretation, 5(1), pp.SD1-SD23.

Evans, S.L. and Jackson, C.A.L., 2019. Base-salt relief controls salt-related deformation in the Outer Kwanza Basin, offshore Angola. Basin Research. DOI: 10.1111/bre.12390.

Evans, S. L., and Jackson, C.A.L., 2020. Intrasalt Structure and Strain Partitioning in Layered Evaporites: Implications for Drilling Through Messinian Salt in the Eastern Mediterranean. EarthArXiv. DOI: 10.31223/osf.io/8pkbz.

Feng, Y.E., Yankelzon, A., Steinberg, J. and Reshef, M., 2016. Lithology and characteristics of the Messinian evaporite sequence of the deep Levant Basin, eastern Mediterranean. Marine Geology, 376, pp.118-131.

Feng, Y.E. and Reshef, M., 2016. The Eastern Mediterranean Messinian salt-depth imaging and velocity analysis considerations. Petroleum Geoscience, 22(4), pp.333-339.

Feng, Y.E., Steinberg, J. and Reshef, M., 2017. Intra-salt deformation: Implications for the evolution of the Messinian evaporites in the Levant Basin, eastern Mediterranean. Marine and Petroleum Geology, 88, pp.251-267.

Friedrich, A.M., Wernicke, B.P., Niemi, N.A., Bennett, R.A. \& Davis, J.L., 2003. Comparison of geodetic and geologic data from the Wasatch region, Utah, and implications for the spectral character of Earth deformation at periods of 10 to 10 million years, J. geophys. Res., 108, doi:10.1029/2001JB000682.

Gautier, F., G. Clauzon, J.P. Suc, J. Cravatte and D. Violanti, 1994, Age and duration of the Messinian salinity crisis: R. Acad. Sci., Paris (IIA) 318, p. 1103-1109.

Gardosh, M.A. and Druckman, Y., 2006. Seismic stratigraphy, structure and tectonic evolution of the Levantine Basin, offshore Israel. Geological Society, London, Special Publications, 260(1), pp.201-227. 

strike-slip tectonics on the evolution of the northern Levant Basin (offshore Lebanon). Tectonics, 33(11), pp.2121-2142.

Ghalayini, R., Homberg, C., Daniel, J.M. and Nader, F.H., 2017. Growth of layer-bound normal faults under a regional anisotropic stress field. Geological Society, London, Special Publications, 439(1), pp.57-78.

Ghalayini, R., Nader, F.H., Bou Daher, S., Hawie, N. and Chbat, W.E., 2018. Petroleum systems of Lebanon: an update and review. Journal of Petroleum Geology, 41(2), pp.189-214.

Gvirtzman, Z., M. Reshef, O. Buch-Leviatan and Z. Ben-Avraham, 2013, Intense salt deformation in the Levant Basin in the middle of the Messinian salinity crisis: Earth and Planetary Science Letters, 379, 108-119.

Gvirtzman, Z., Manzi, V., Calvo, R., Gavrieli, I., Gennari, R., Lugli, S., Reghizzi, M. and Roveri, M., 2017. Intra-Messinian truncation surface in the Levant Basin explained by subaqueous dissolution. Geology, 45(10), pp.915-918.

Hall, J., Calon, T.J., Aksu, A.E. and Meade, S.R., 2005. Structural evolution of the Latakia Ridge and pp.261-297.

Hawie, N., Gorini, C., Deschamps, R., Nader, F.H., Montadert, L., Granjeon, D. and Baudin, F., 2013. 664 Tectono-stratigraphic evolution of the northern Levant Basin (offshore Lebanon). Marine and petroleum geology, 48, pp.392-410.

Hudec, M.R. and Jackson, M.P., 2007. Terra infirma: Understanding salt tectonics. Earth-Science 667 Reviews, 82(1-2), pp.1-28.

Inati, L., Zeyen, H., Nader, F.H., Adelinet, M., Sursock, A., Rahhal, M.E. and Roure, F., 2016. Lithospheric architecture of the Levant Basin (Eastern Mediterranean region): A 2D modeling approach. Tectonophysics, 693, pp.143-156.

Jackson, M.P.A., B.C. Vendeville and D.D. Schultz-Ela, 1994, Structural dynamics of salt systems: Annual Review of Earth and Planetary Sciences, 22(1), pp.93-117.

673 Jackson, M.P. and Hudec, M.R., 2005. Stratigraphic record of translation down ramps in a passive674 margin salt detachment. Journal of Structural Geology, 27(5), pp.889-911. Jackson, M.P., Hudec, M.R., 2017. Salt Tectonics: Principles and Practice. Cambridge University Press. Jones, I.F. and Davison, I., 2014. Seismic imaging in and around salt bodies. Interpretation, 2(4), pp.SL1677 SL20.

678 Kartveit, K.H., Omosanya, K.O., Johansen, S.E., Eruteya, O.E., Reshef, M. and Waldmann, N.D., 2018. 679 Multiphase structural evolution and geodynamic implications of Messinian salt-related structures, 680 levant basin, offshore Israel. Tectonics, 37(5), pp.1210-1230.

681 Kirkham, C., Cartwright, J., Bertoni, C., Rodriguez, K. and Hodgson, N., 2019. 3D kinematics of a thick 682 salt layer during gravity-driven deformation. Marine and Petroleum Geology, 110, pp.434-449. 
Kirkham, C., Bertoni, C., Cartwright, J., Lensky, N.G., Sirota, I., Rodriguez, K. and Hodgson, N., 2020. The demise of a 'salt giant'driven by uplift and thermal dissolution. Earth and Planetary Science Letters, 531, p.115933.

Marton, L.G., Tari, G.C. and Lehmann, C.T., 2000. Evolution of the Angolan passive margin, West Africa, with emphasis on post-salt structural styles. Geophysical Monograph-American Geophysical Union, 115, pp.129-150.

Matmon, A., Enzel, Y., Zilberman, E. and Heimann, A., 1999. Late Pliocene and Pleistocene reversal of drainage systems in northern Israel: tectonic implications. Geomorphology, 28(1-2), pp.43-59.

McClymont, A.F., Villamor, P. \& Green, A.G., 2009. Fault displacement accumulation and slip rate variability within the Taupo Rift (New Zealand) based on trench and 3-D ground-penetrating radar data, Tectonics, 28, TC4005, doi:10.1029/2008TC002334.

Meilijson, A., Hilgen, F., Sepúlveda, J., Steinberg, J., Fairbank, V., Flecker, R., Waldmann, N.D., Spaulding, S.A., Bialik, O.M., Boudinot, F.G. and Illner, P., 2019. Chronology with a pinch of salt: Integrated stratigraphy of Messinian evaporites in the deep Eastern Mediterranean reveals longlasting halite deposition during Atlantic connectivity. Earth-Science Reviews.

Mitchell, S.G., Matmon, A., Bierman, P.R., Enzel, Y., Caffee, M. \& Rizzo, D., 2001. Displacement history of a limestone normal fault scarp, northern Israel, from cosmogenic $36 \mathrm{Cl}$, J. geophys. Res., 106, 42474264.

Mukherjee, S., Talbot, C.J. and Koyi, H.A., 2010. Viscosity estimates of salt in the Hormuz and Namakdan salt diapirs, Persian Gulf. Geological Magazine, 147(4), pp.497-507.

Nader, F.H., Inati, L., Ghalayini, R., Hawie, N. and Daher, S.B., 2018. Key geological characteristics of the Saida-Tyr Platform along the eastern margin of the Levant Basin, offshore Lebanon: implications for hydrocarbon exploration. Oil \& Gas Science and Technology-Revue d'IFP Energies nouvelles, 73, p.50.

Nicol, A.,Walsh, J., Berryman, K. \& Villamor, P., 2006. Interdependence of fault displacement rates and paleoearthquakes in an active rift, Geology, 34, 865-868.

Oppo, D., Evans, S., lacopini, D., Kabir, M., Maselli, V., Jackson C. A-L., 2020. Leaky salt: pipe trails record the history of cross-evaporite fluid escape in the northern Levant Basin, Eastern Mediterranean, EarthArXiv.

Peel, F.J., 2014. The engines of gravity-driven movement on passive margins: Quantifying the relative contribution of spreading vs. gravity sliding mechanisms. Tectonophysics, 633, pp.126-142.

Pichel, L.M., Peel, F., Jackson, C.A. and Huuse, M., 2018. Geometry and kinematics of salt-detached ramp syncline basins. Journal of Structural Geology, 115, pp.208-230.

Pichel, L.M., Jackson, C.A.L., Peel, F. and Dooley, T.P., 2019. Base-salt relief controls salt-tectonic structural style, São Paulo Plateau, Santos Basin, Brazil. Basin Research, 32(3), pp.453-484.

Quirk, D.G., Schødt, N., Lassen, B., Ings, S.J., Hsu, D., Hirsch, K.K. and Von Nicolai, C., 2012. Salt tectonics on passive margins: examples from Santos, Campos and Kwanza basins. Geological Society, London, Special Publications, 363(1), pp.207-244.

Raith, A.F., Strozyk, F., Visser, J. and Urai, J.L., 2016. Evolution of rheologically heterogeneous salt structures: a case study from the NE Netherlands. Solid Earth, 7(1), p.67. 
Reiche, S., Hübscher, C. and Beitz, M., 2014. Fault-controlled evaporite deformation in the Levant Basin, Eastern Mediterranean. Marine Geology, 354, pp.53-68.

Robinson, R., Nicol, A., Walsh, J.J. \& Villamor, P., 2009. Features of earthquake recurrence in a complex normal fault network: results from a synthetic seismicity model of the Taupo Rift, New Zealand, J. geophys. Res., 114, B12306, doi:10.1029/2008JB006231.

Roveri, M., R. Flecker, W. Krijgsman, J. Lofi, S. Lugli, V. Manzi, F.J. Sierro, A. Bertini, A. Camerlenghi, G. De Lange, R. Govers, F.J. Hilgen, C. Hübscher, P.T. Meijer, \& M. Stoica, 2014, The Messinian salinity crisis: Past and future of a great challenge for marine sciences: Marine Geology, 352, 25-58.

Rowan, M.G., Urai, J.L., Fiduk, J.C. and Kukla, P.A., 2019. Deformation of intrasalt competent layers in different modes of salt tectonics. Solid Earth, 10(3), pp.987-1013.

Ryan, W.B.F., 2009, Decoding the Mediterranean salinity crisis: Sedimentology 56, 95-136.

Schlagenhauf, A., Gaudemer, Y., Benedetti, L., Manighetti, I., Palumbo, L., Schimmelpfennig, I., Finkel, R. \& Pou, K., 2010. Using in situ Chlorine-36 cosmonuclide to recover past earthquake histories on limestone normal fault scarps: a reappraisal of methodology and interpretations, Geophys. J. Int., 182, 36-72, doi:10.1111/j.1365-246X.2010.04622.x.

Schlagenhauf, A., Manighetti, I., Benedetti, L., Gaudemer, Y., Finkel, R., Malavieille, J.\&Pou, K., 2011. Earthquake supercycles in central Italy inferred from $36 \mathrm{Cl}$ exposure dating, Earth planet. Sci. Letts., 307, 487-500, doi:10.1016/j.epsl.2011.05.022.

Schultz-Ela, D.D., 2001. Excursus on gravity gliding and gravity spreading. Journal of structural geology, 23(5), pp.725-731.

Spiers, C.J., Schutjens, P.M.T.M., Brzesowsky, R.H., Peach, C.J., Liezenberg, J.L. and Zwart, H.J., 1990. Experimental determination of constitutive parameters governing creep of rocksalt by pressure solution. Geological Society, London, Special Publications, 54(1), pp.215-227.

Urai, J.L., and Spiers, C.J., 2007. The effect of grain boundary water on deformation mechanisms and rheology of rocksalt during long-term deformation, in Wallner, M., et al., eds., Proceedings of the $6^{\text {th }}$ Conference on the Mechanical Behaviour of Salt: Understanding of THMC Processes in Salt Rocks: London, Taylor and Francis, p. 149-158.

Urai, J.L., Schléder, Z., Spiers, C.J., and Kukla, P.A., 2008, Flow and transport properties of salt rocks, in Littke, R.,et al., eds., Dynamics of Complex Intracontinental Basins: The Central European Basin System: Berlin, Heidelberg, Springer-Verlag, p. 277-290.

Van Keken, P.E., Spiers, C.J., Van den Berg, A.P. and Muyzert, E.J., 1993. The effective viscosity of rocksalt: implementation of steady-state creep laws in numerical models of salt diapirism. Tectonophysics, 225(4), pp.457-476.

Weijermars, R., Jackson, M.T. and Vendeville, B., 1993. Rheological and tectonic modeling of salt provinces. Tectonophysics, 217(1-2), pp.143-174. 
758 Figures

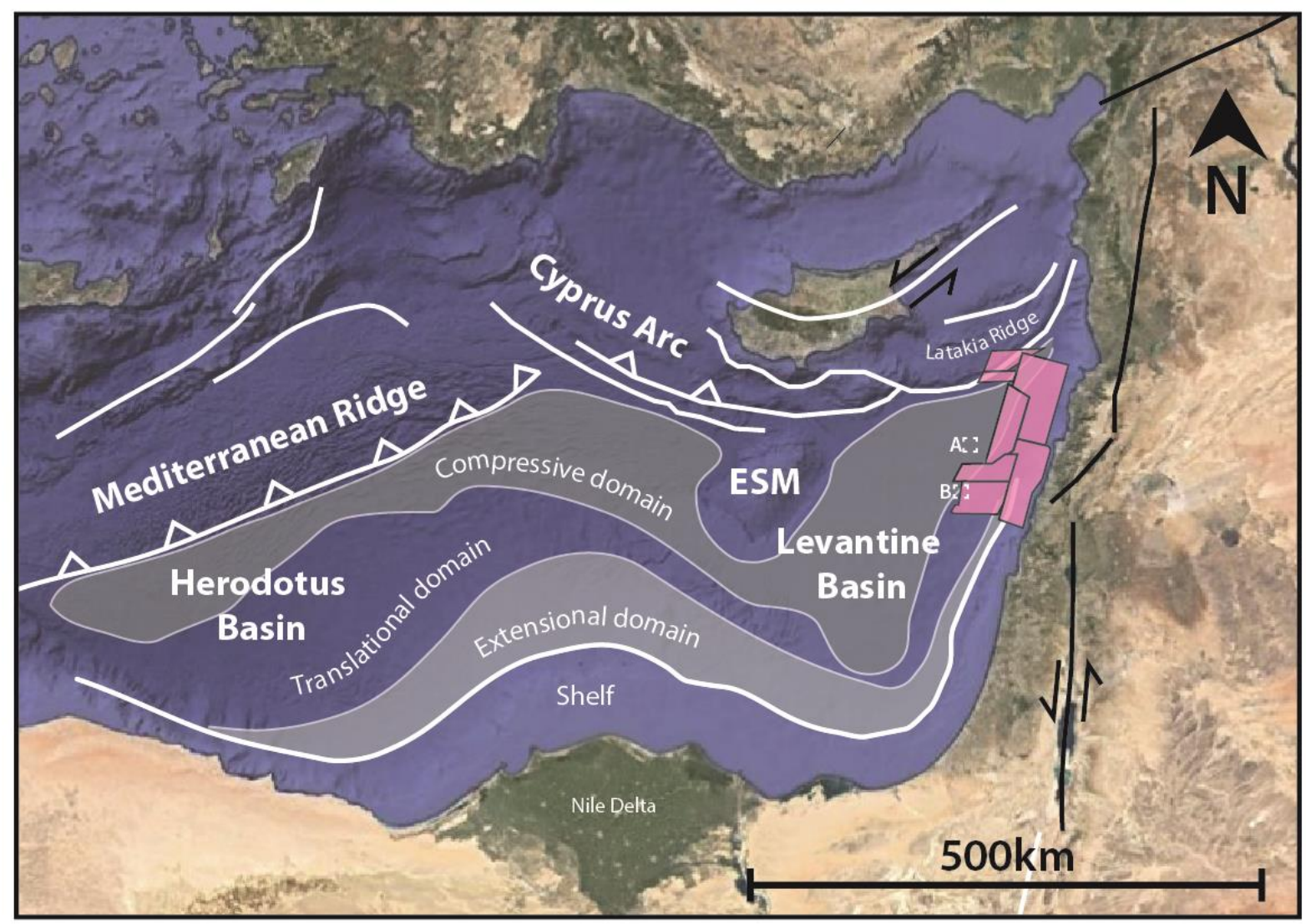

Figure 1 Location of dataset (pink polygon) and distribution of key tectonic elements in the Eastern 760 Mediterranean. Boxes A and B denote location of previous studies of the Oceanus Structure 761 (Cartwright et al., 2018) and the Saida-Tyr Structure (Kirkham et al., 2019), respectively. 

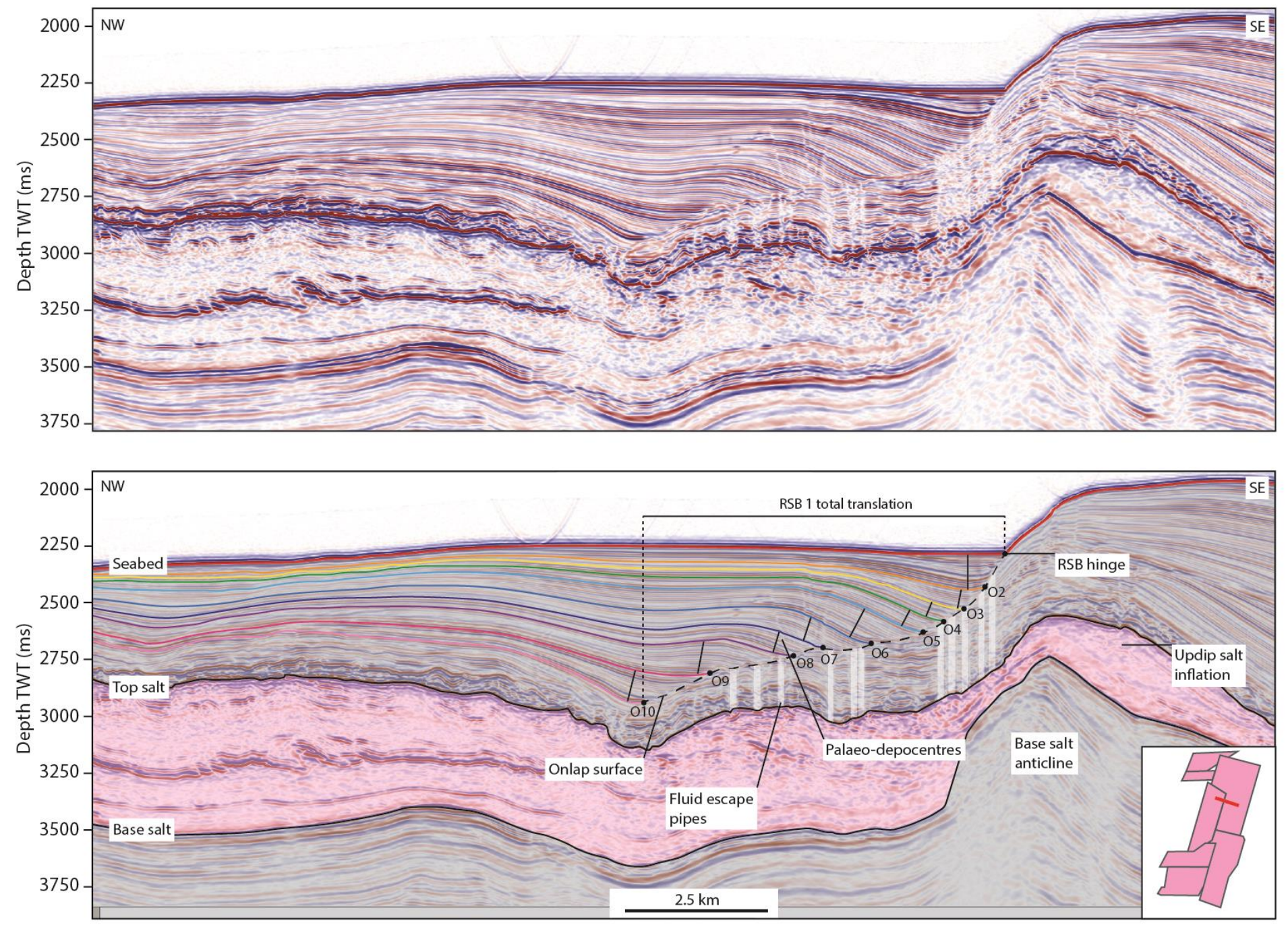

762 Figure 2 Seismic cross section showing base-salt anticline and associated ramp syncline basin downdip (RSB 1). Coloured lines show mapped intra-RSB 763 horizons. Vertical white lines show fluid escape pipes. RSB depocentres form adjacent to the crest of the anticline and is subsequently translated downdip, 764 preserving a stratigraphic record of downdip translation. 


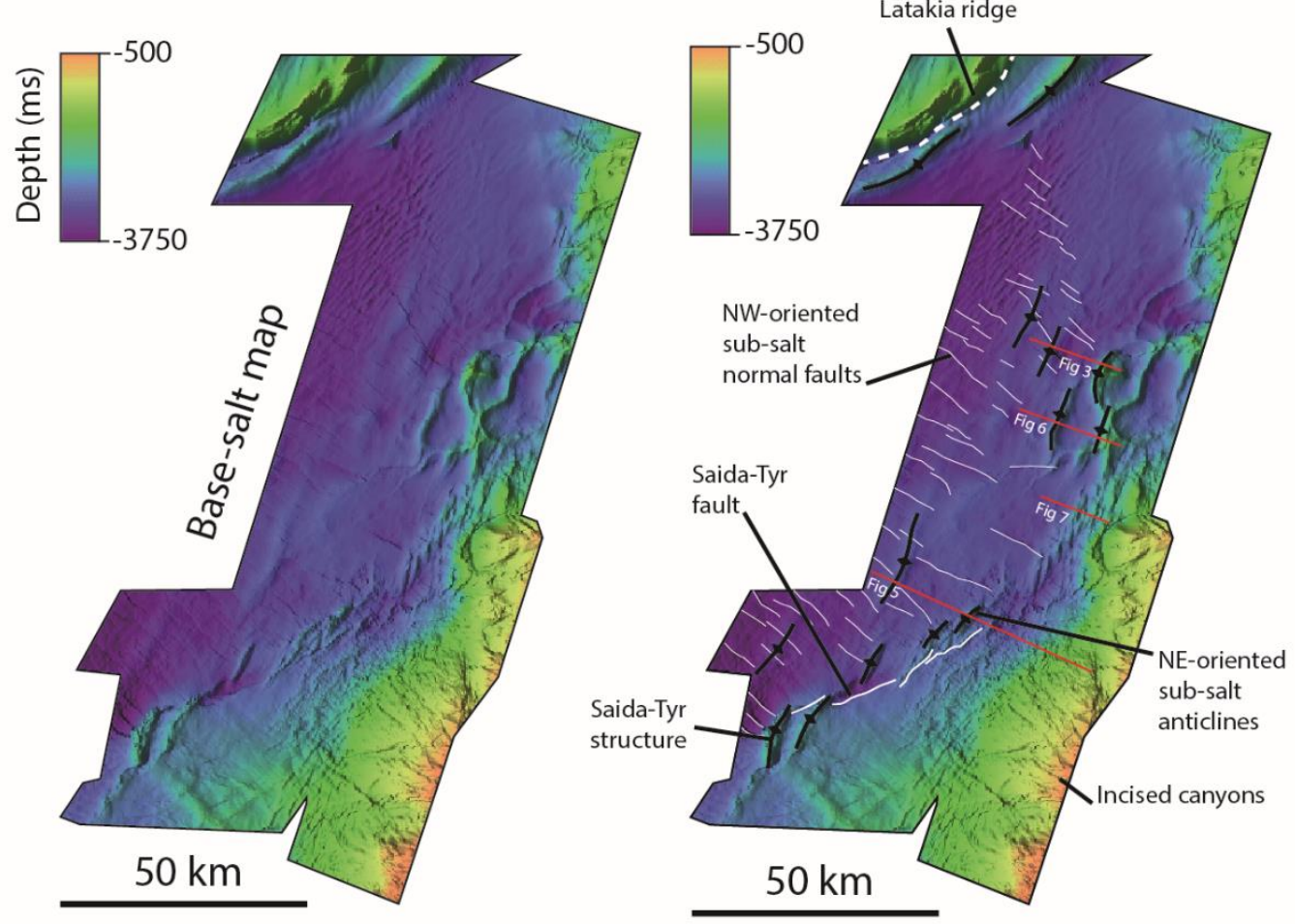

765 Figure 3 TWT depth map of the base-salt surface showing the distribution of NE-trending anticlines 766 (black) and NW-trending normal faults (white). Red lines show locations of seismic sections used in 767 other figures.
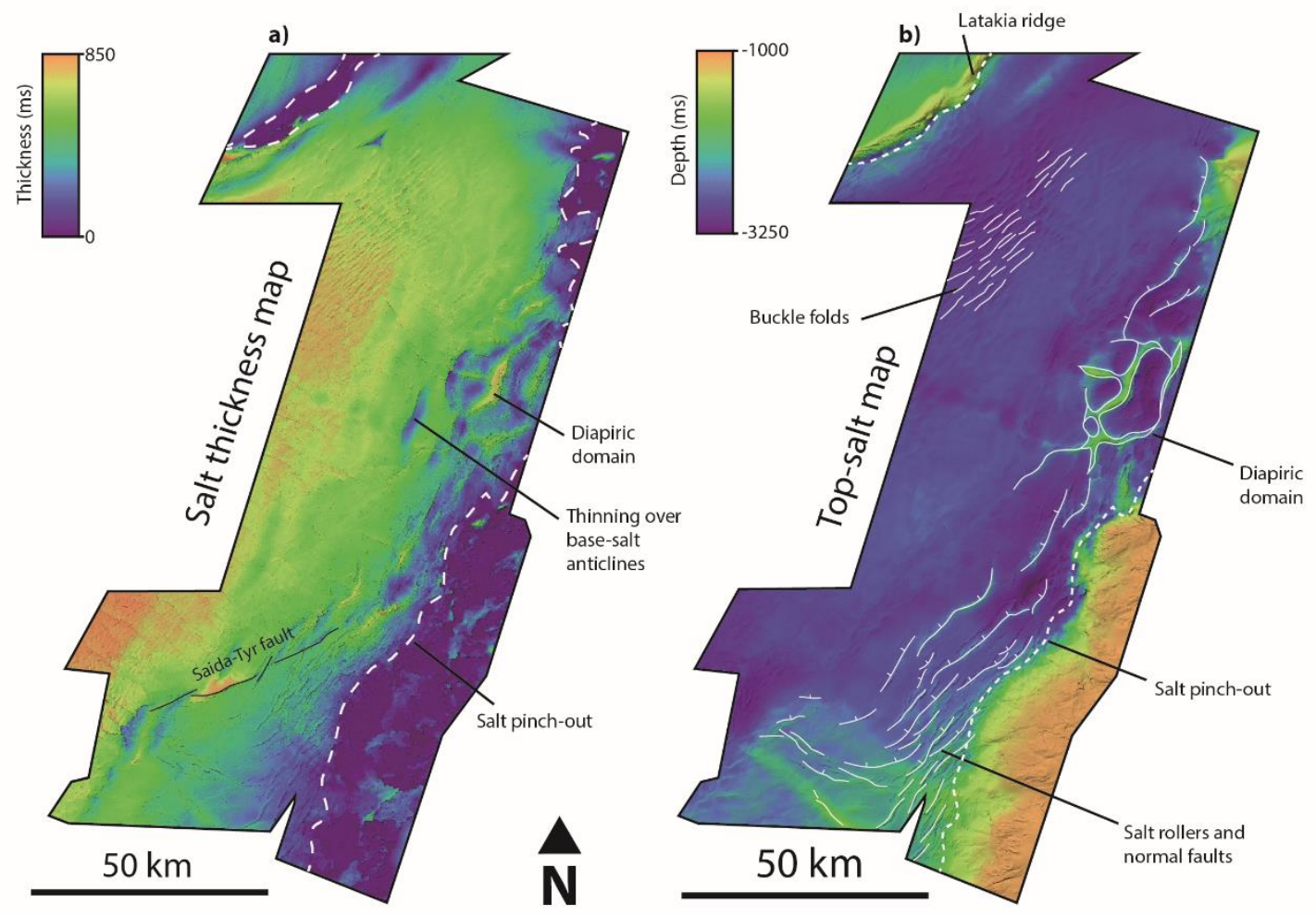

Figure 4 (a) Salt thickness map showing thinning over base-salt anticlines and pinch-out updip onto the Levant margin. (b) Top-salt depth map showing extensional structures along the margin and buckle folds around the Latakia Ridge. 

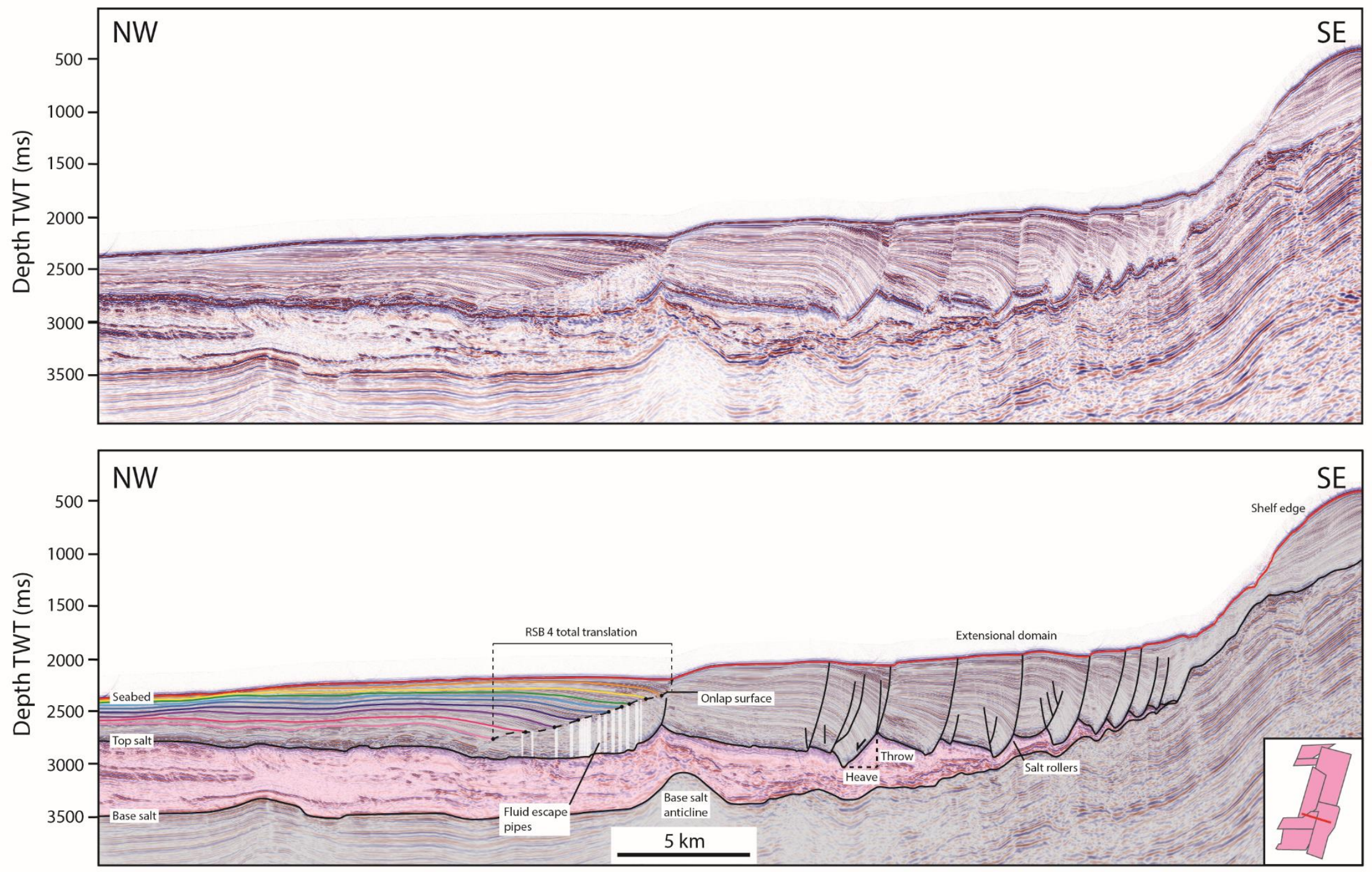

Figure 5 Seismic cross section showing thin-skinned extensional faults facilitating basinward translation of the overburden across the base-salt anticline.

Coloured lines show mapped intra-RSB horizons. Vertical white lines show fluid escape pipes. 

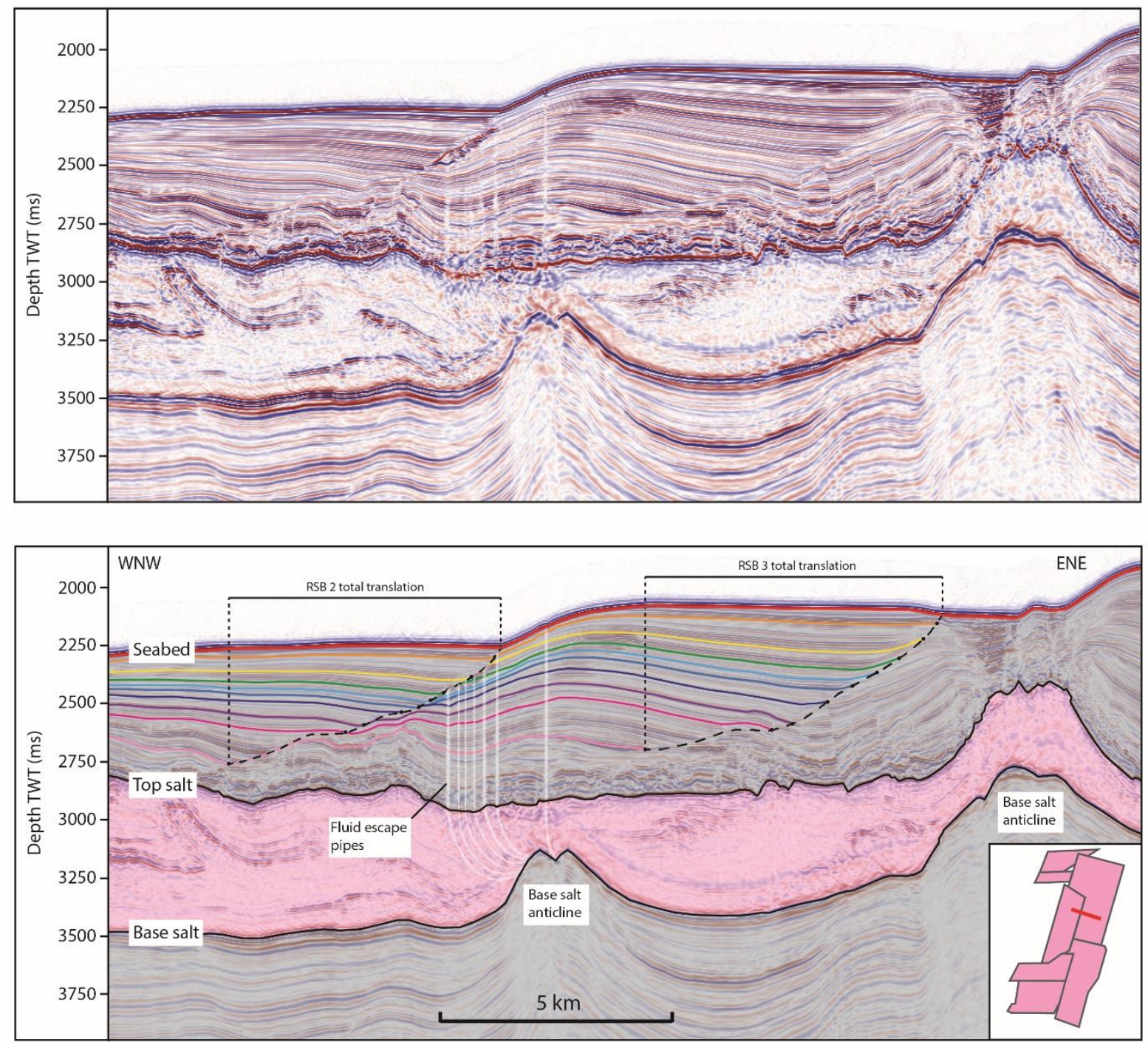

Figure 6 Dual ramp syncline basins adjacent to parallel base-salt anticlines (basinward RSB 2 and landward RSB 3). Coloured lines show mapped intra-RSB horizons. Vertical white lines show fluid escape pipes. 

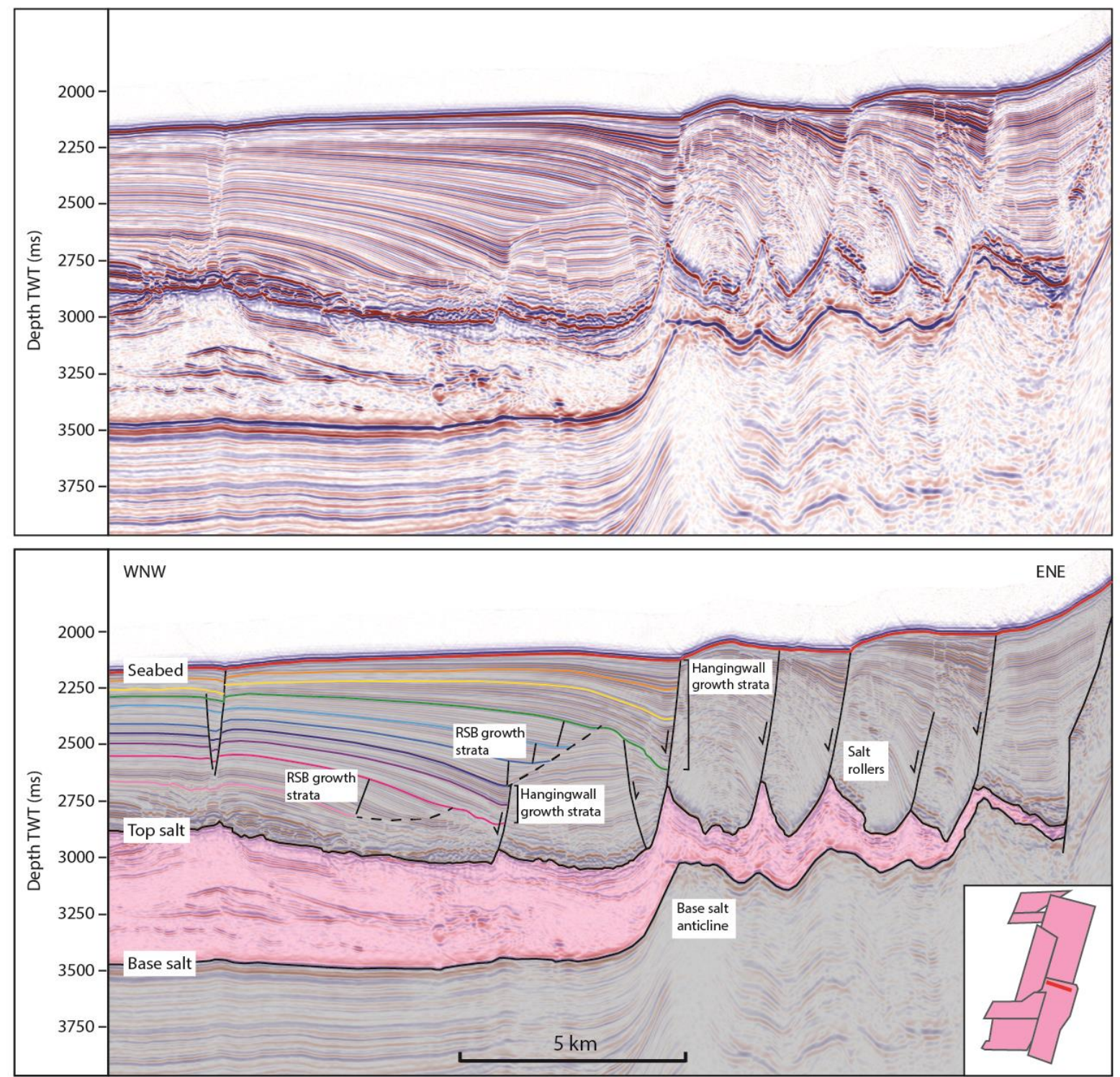

Figure 7 Disrupted RSB development due to intermittent normal faulting. Packages of RSB growth strata and hangingwall growth strata indicate phases of continuous translation and phases of faulting.

778 Coloured lines show mapped intra-RSB horizons. 

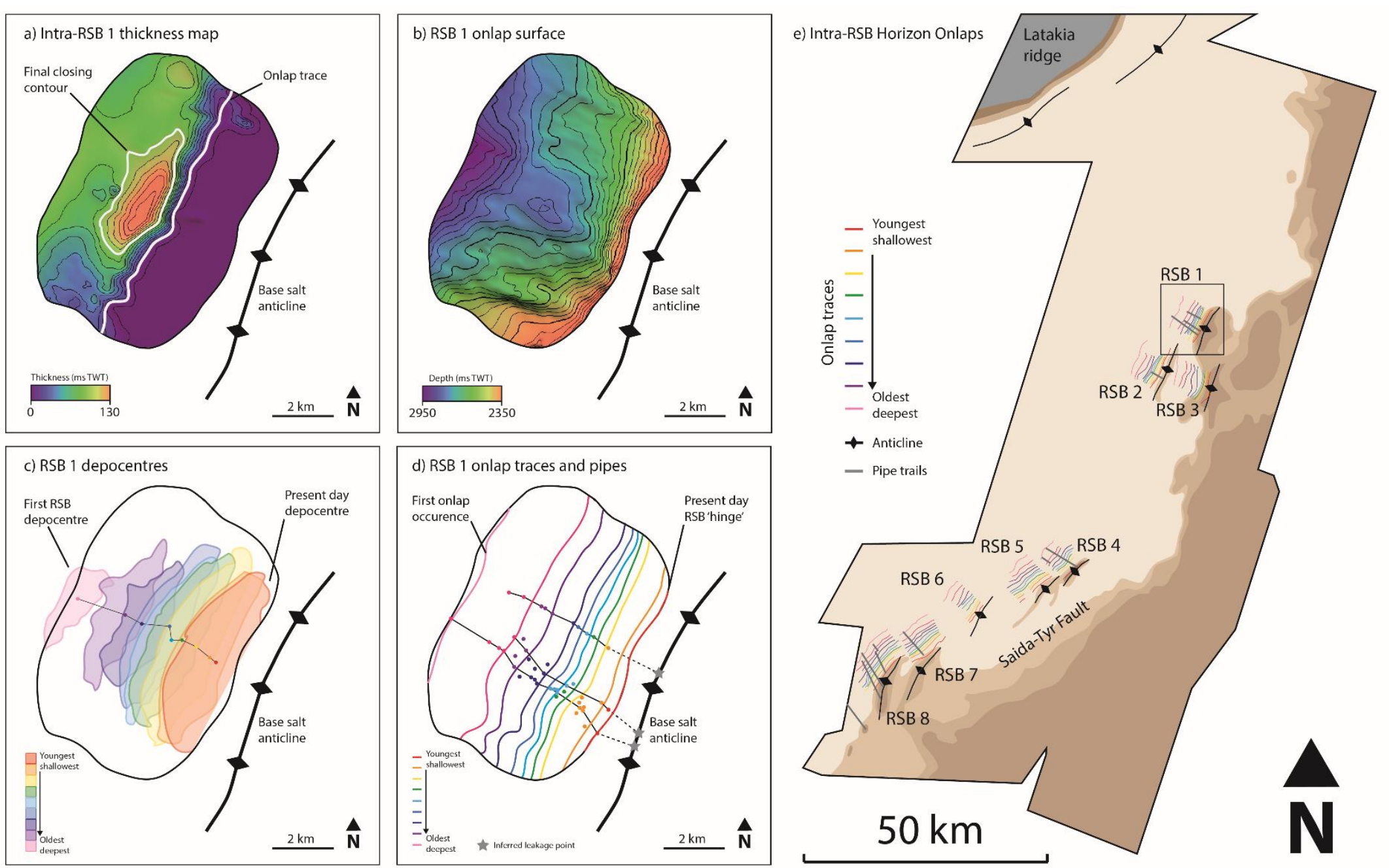

Figure 8 (a) Example thickness map of intra-RSB unit showing final closing contour and onlap trace. (b) Geometry of the onlap surface. (c) Stacked RSB depocentre outlines showing their migration away from the anticline with increasing age. Tracing the thickest succession of each unit gives the direction of translation. (d) Mapped onlap traces for RSB 1 and fluid escape pipe trails coloured by age of corresponding intra-RSB unit. (e) Distribution of base-salt anticlines and mapped onlap traces for RSBs presented in this study. Grey lines show associated pipe trails. Square indicates location of (a-d). 
a) RSB 4 top salt variance map

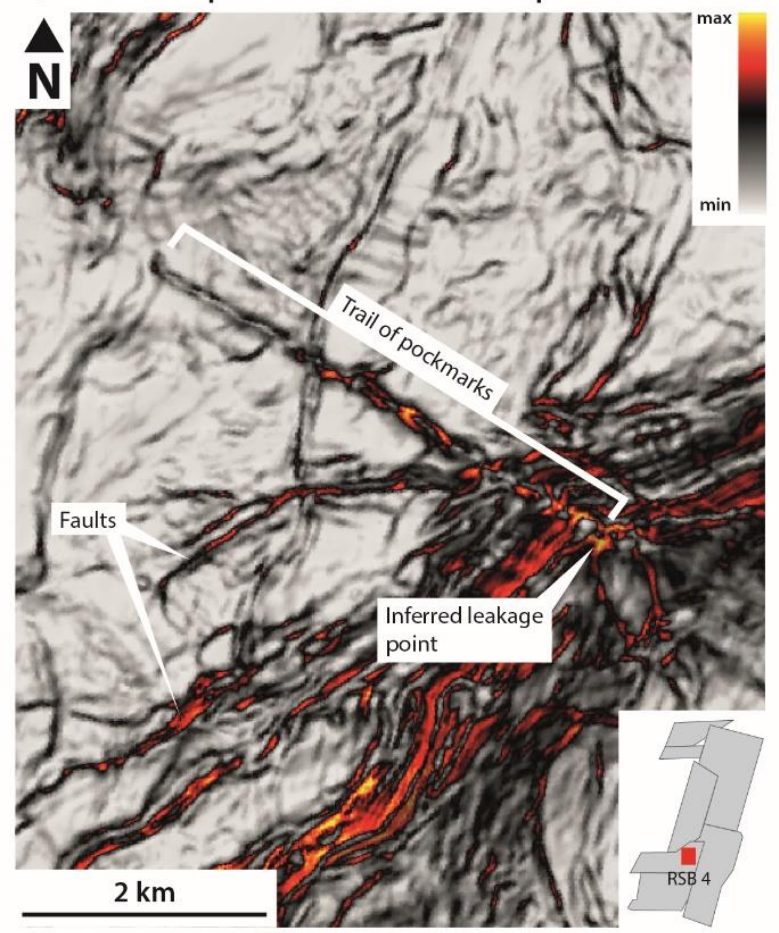

b) RSB 4 top salt RMS amplitude map

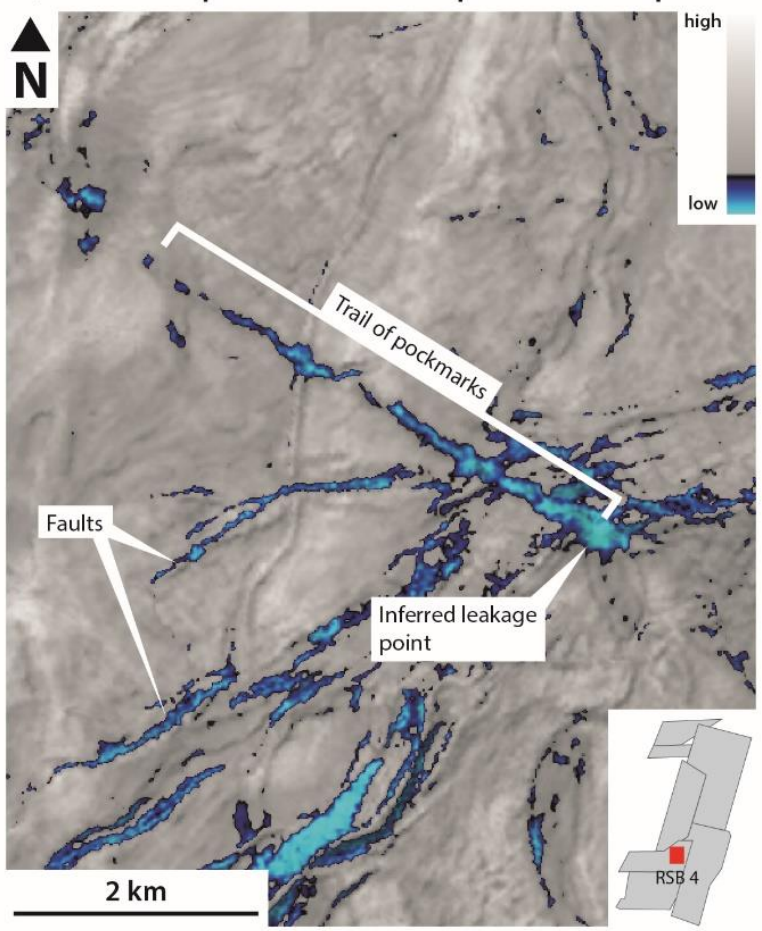

Figure 9 Variance (a) and RMS amplitude (b) maps of the top-salt surface showing the RSB 4 pipe trail. Location shown in inset. 

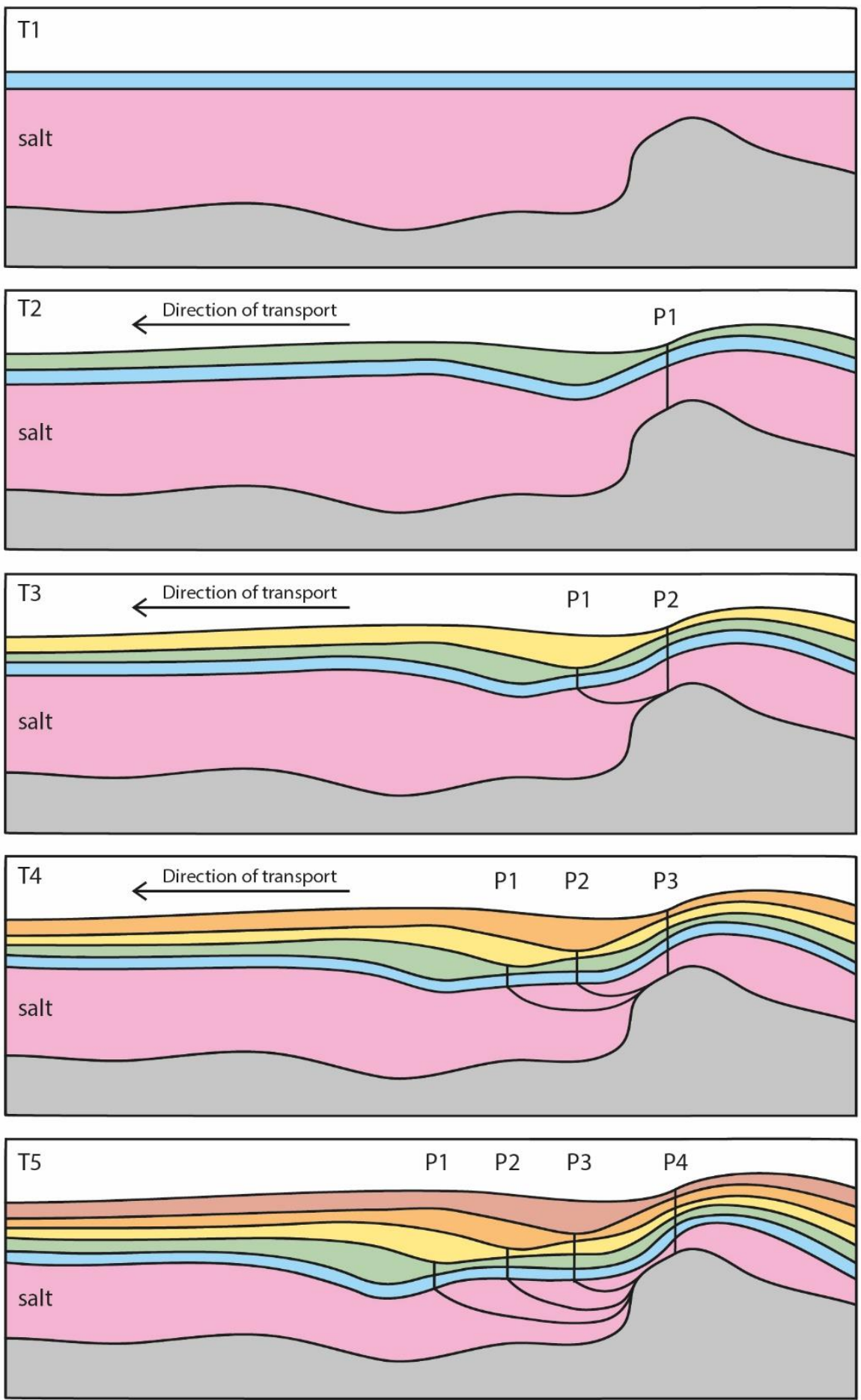

Figure 10 Co-development of ramp syncline basins and fluid escape pipes. Successive RSB depocentres and pipes are progressively translated away from the base-salt high. Pipe age may therefore be constrained by the age of the onlap that the terminus connects to at the base of the RSB. 
a) RSB Total Translations

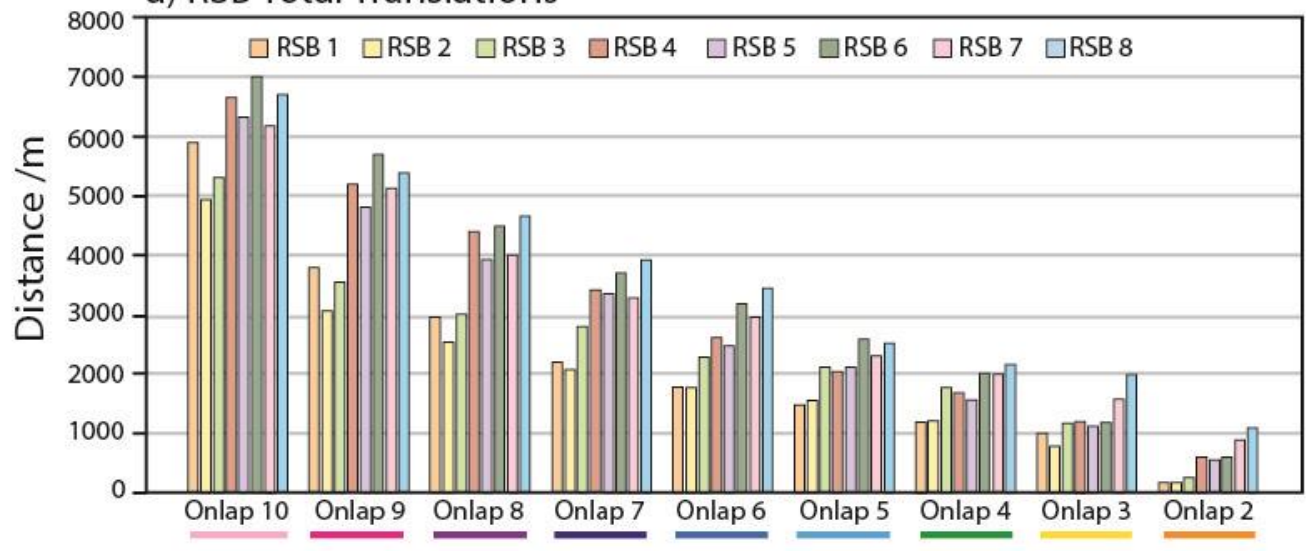

b) RSB Incremental Translations

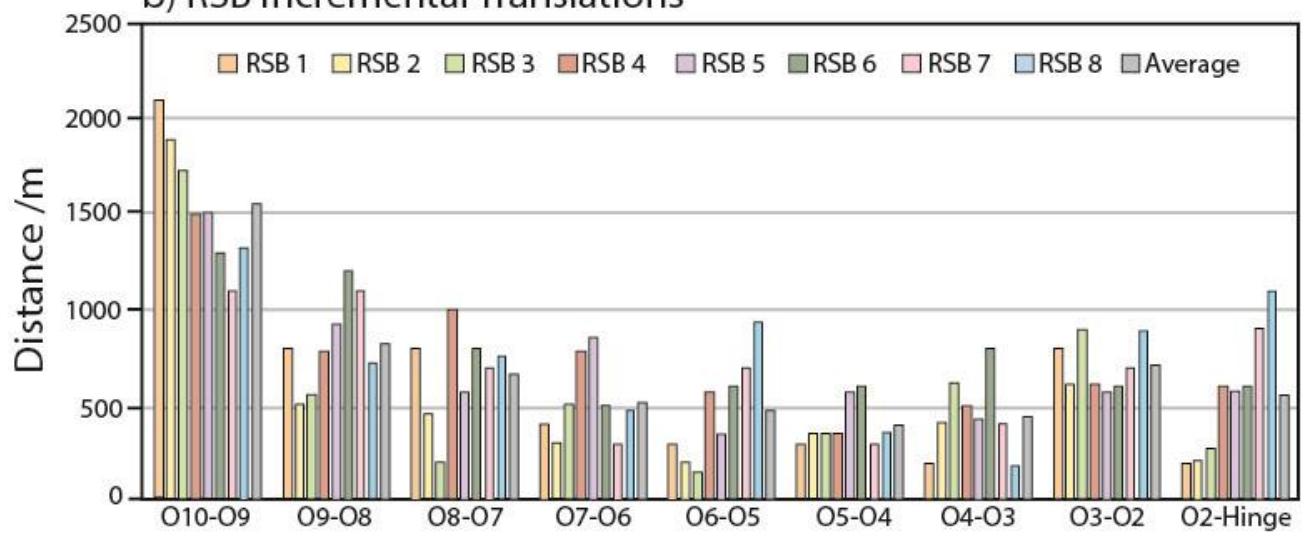

Figure 11 (a) Magnitudes of translation measured for intra-RSB onlaps of equivalent ages in each RSB. The magnitude of translation given by the oldest onlap (Onlap 10) represents the total translation experienced by each RSB. (b) Magnitudes of translation during different time periods, given by the difference between total onlap translations. 010-09 represents the oldest increment of time, with O2-Hinge representing the most recent increment of time. 

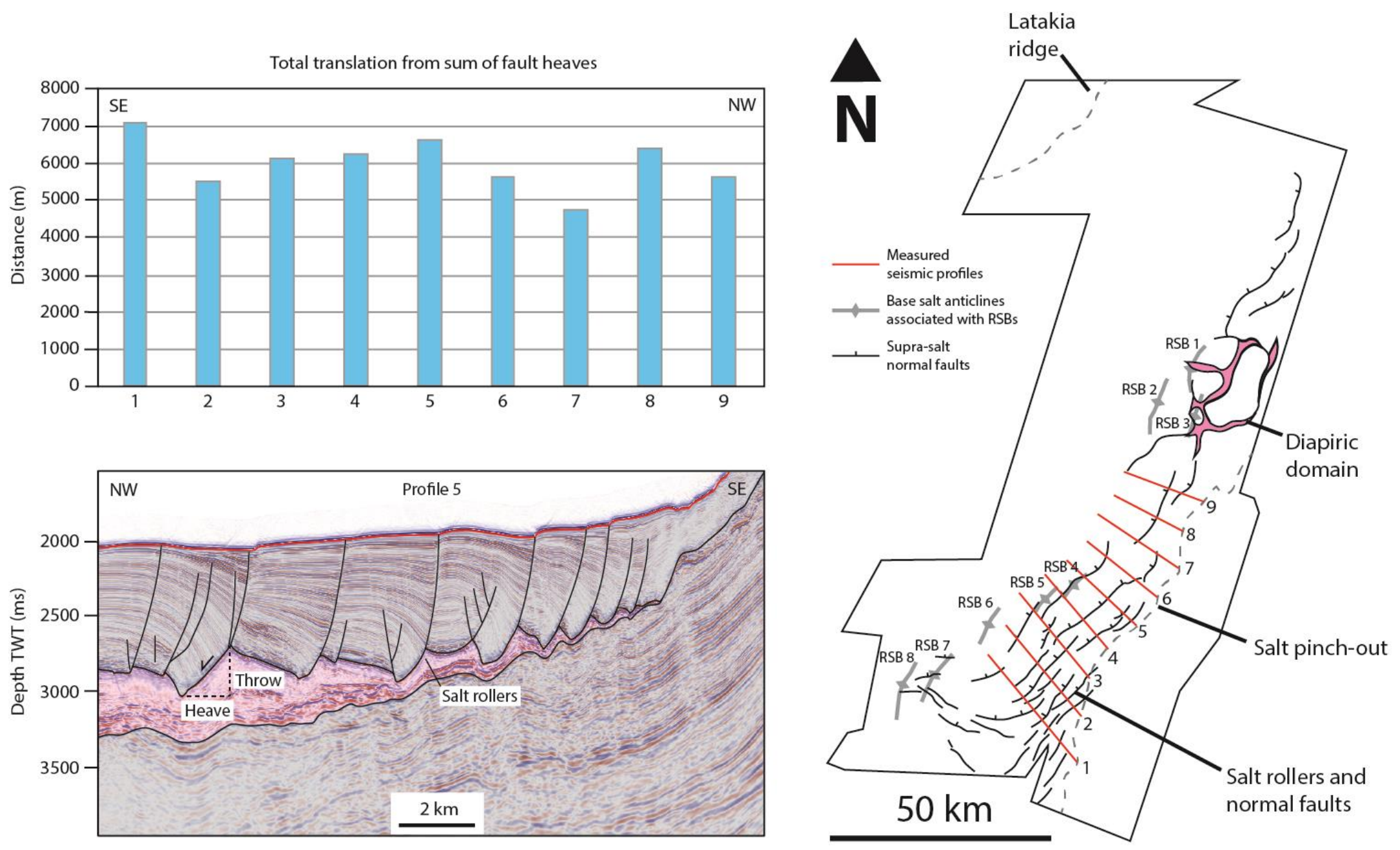

Figure 12 Total translation magnitudes calculated from summing the heaves (horizontal components of fault slip) of normal faults in the updip extensional 


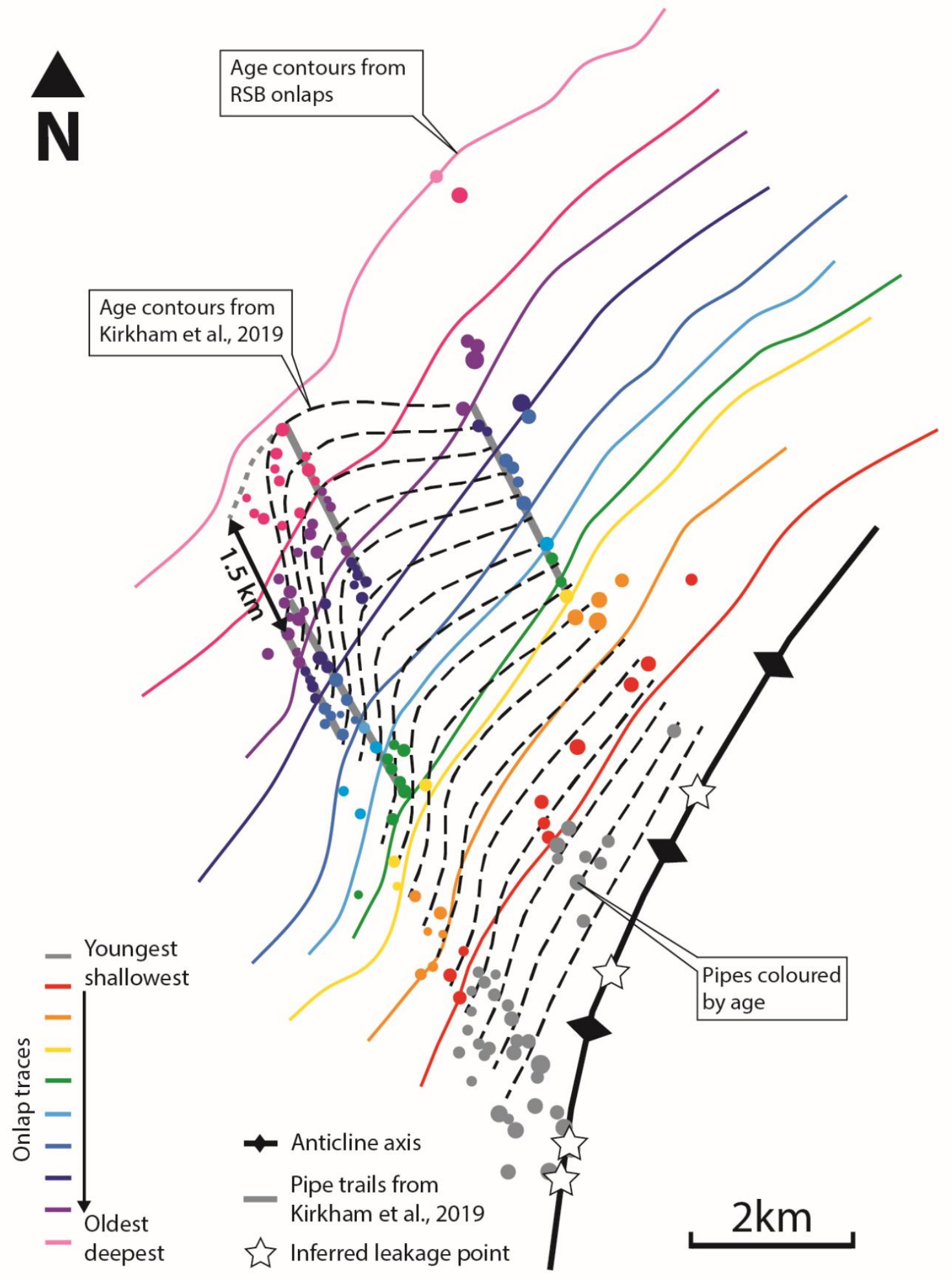

Figure 13 Coloured lines show age contours given by onlap traces for RSB 8. Pipes coloured by age of corresponding intra-RSB unit. Dashed lines show age contours inferred by Kirkham et al., (2019) assuming equivalent age of first pipe in each trail. Sub-parallel onlap traces show uniform translation away from the base-salt anticline. 
a) Large salt flux imbalance
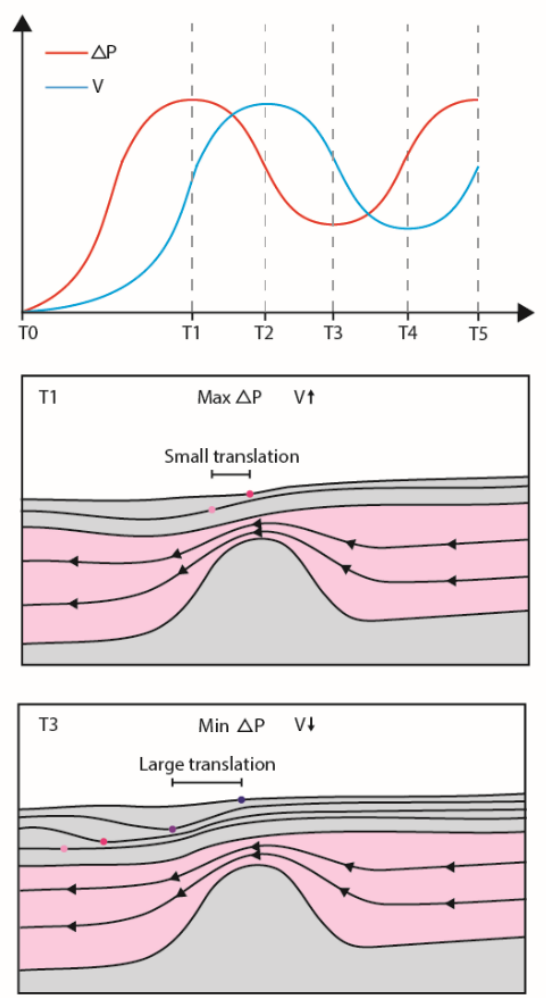
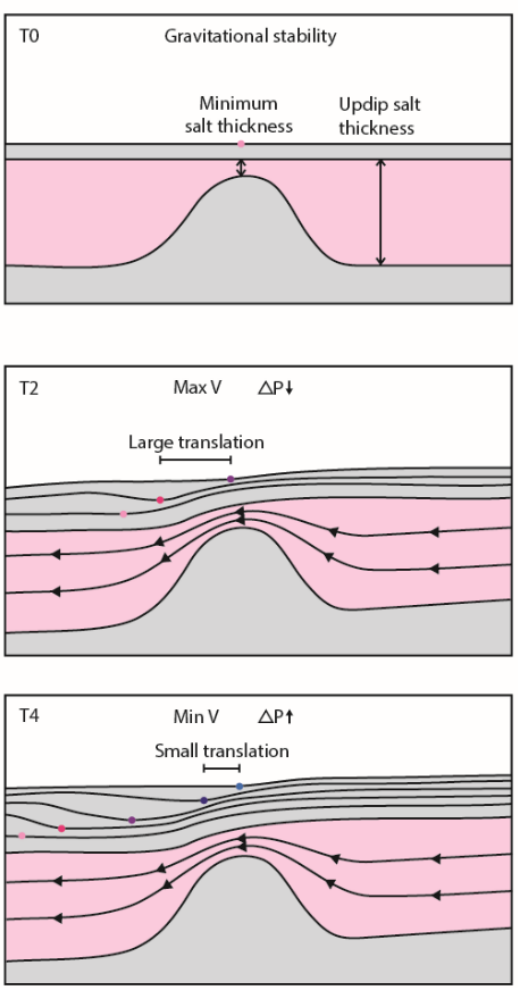

b) Small salt flux imbalance
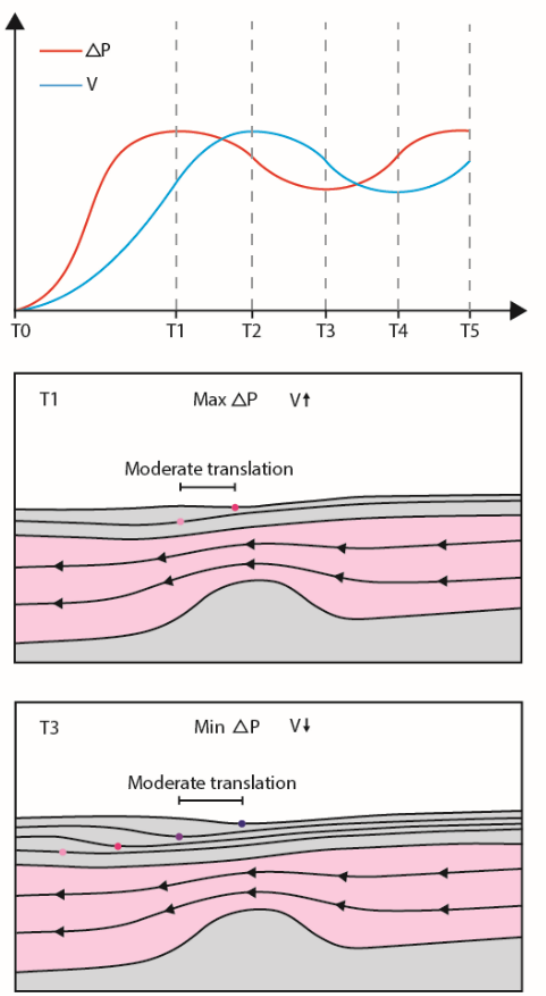
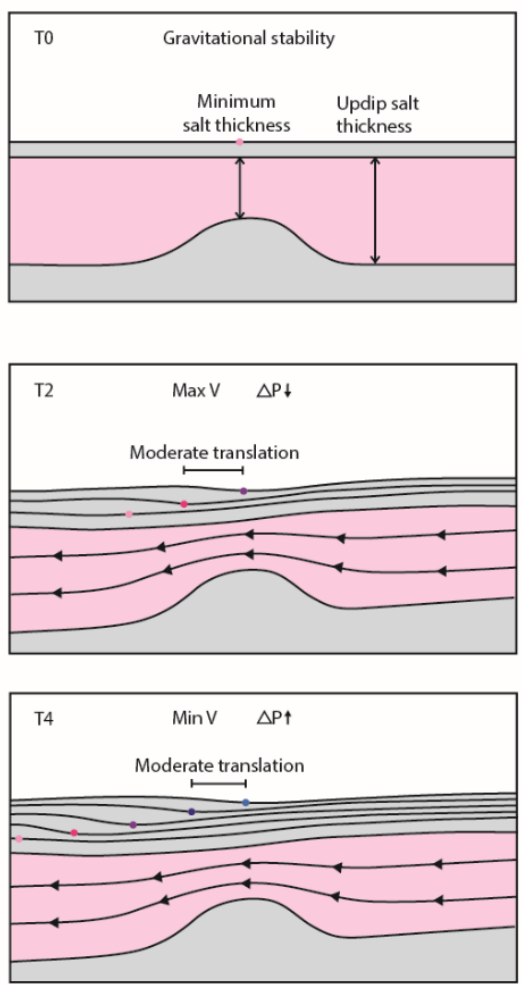

Figure 14 Schematic showing time-varying evolution of pressure and velocity during salt flow over a base-salt anticline. In the first instance, pressure builds within the salt on the updip flank due to the volumetric mismatch (more salt input than output). This process gradually increases the pressure difference ( $\Delta \mathrm{P}$ ) across the anticline (TO-T1). In turn, this pressure difference increases the stress acting upon the salt, and since stress is proportional to strain rate, the velocity of salt flow across the anticline increases (TO-T1). The acceleration of the salt flow is proportional to the pressure difference across the anticline, such that maximum acceleration occurs when $\Delta \mathrm{P}$ is at its peak ( $\mathrm{T} 1$ ). This velocity increase reduces the volumetric imbalance across the anticline and allows the pressure difference to drop (T1-T2). As the system approaches equilibrium, the stress acting on the salt is reduced and it begins to decelerate (T2-T3). The pressure difference across the anticline then starts to build up again, and the process repeats (T3-T4). The feedback between pressure difference and velocity therefore causes them to vary in a cyclical nature. Pressure and velocity variations are more extreme for a large salt flux imbalance (a) than a small salt flux imbalance (b). 

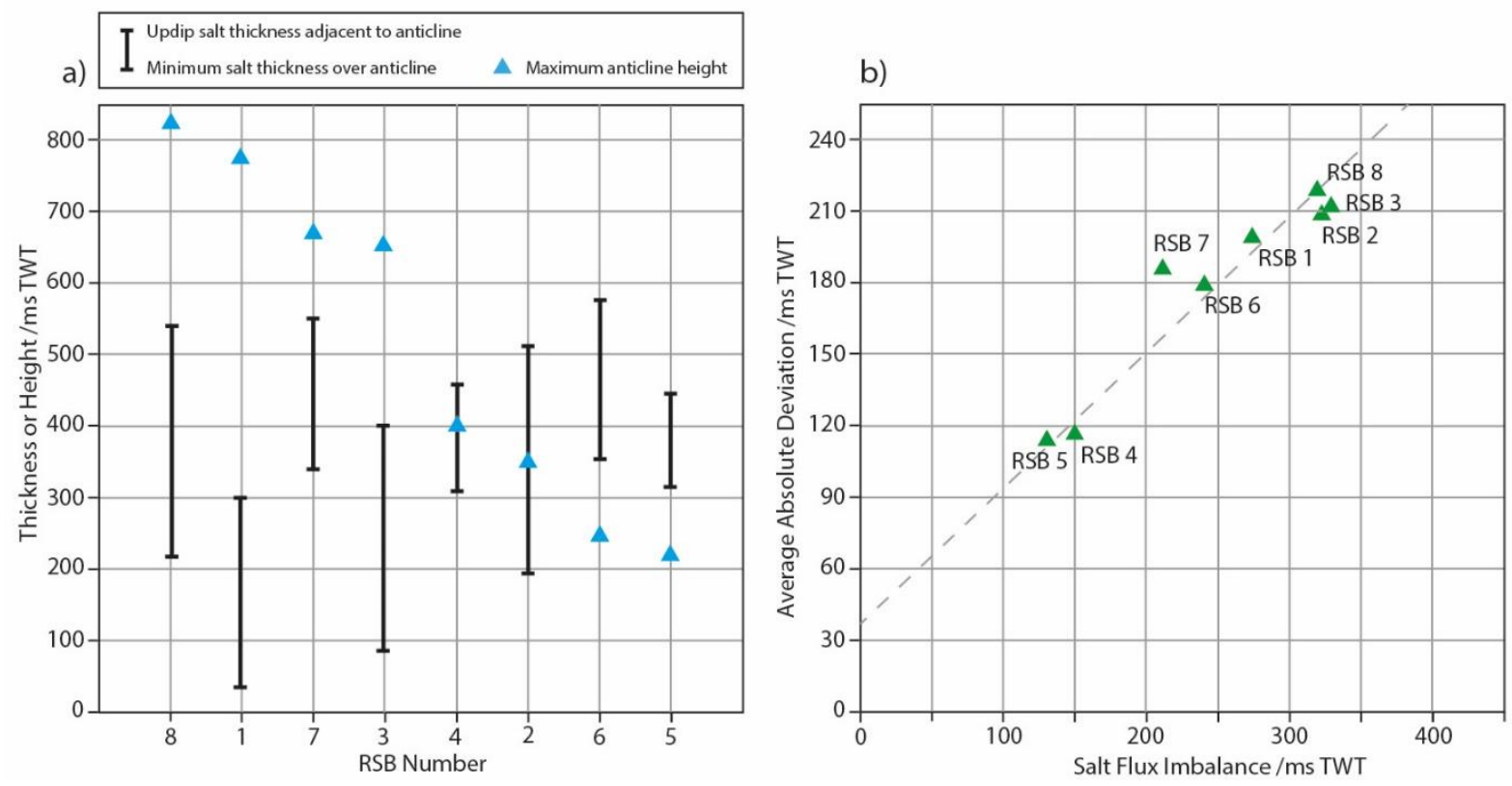

Figure 15 (a) Plot of anticline height, adjacent salt thickness and minimum salt thickness over the crest for each RSB, ordered from largest to smallest anticline height. The difference between adjacent updip salt thickness and minimum thickness over the crest is a proxy for the magnitude of salt flux imbalance. (b) The absolute average deviation of each RSB is proportional to its salt flux imbalance. This means that RSBs with a large salt flux imbalance show more extreme variability in relative translation rate with respect to the average at each time interval than those with a small salt flux imbalance. The $R^{2}$ value for this correlation is 0.9 . 


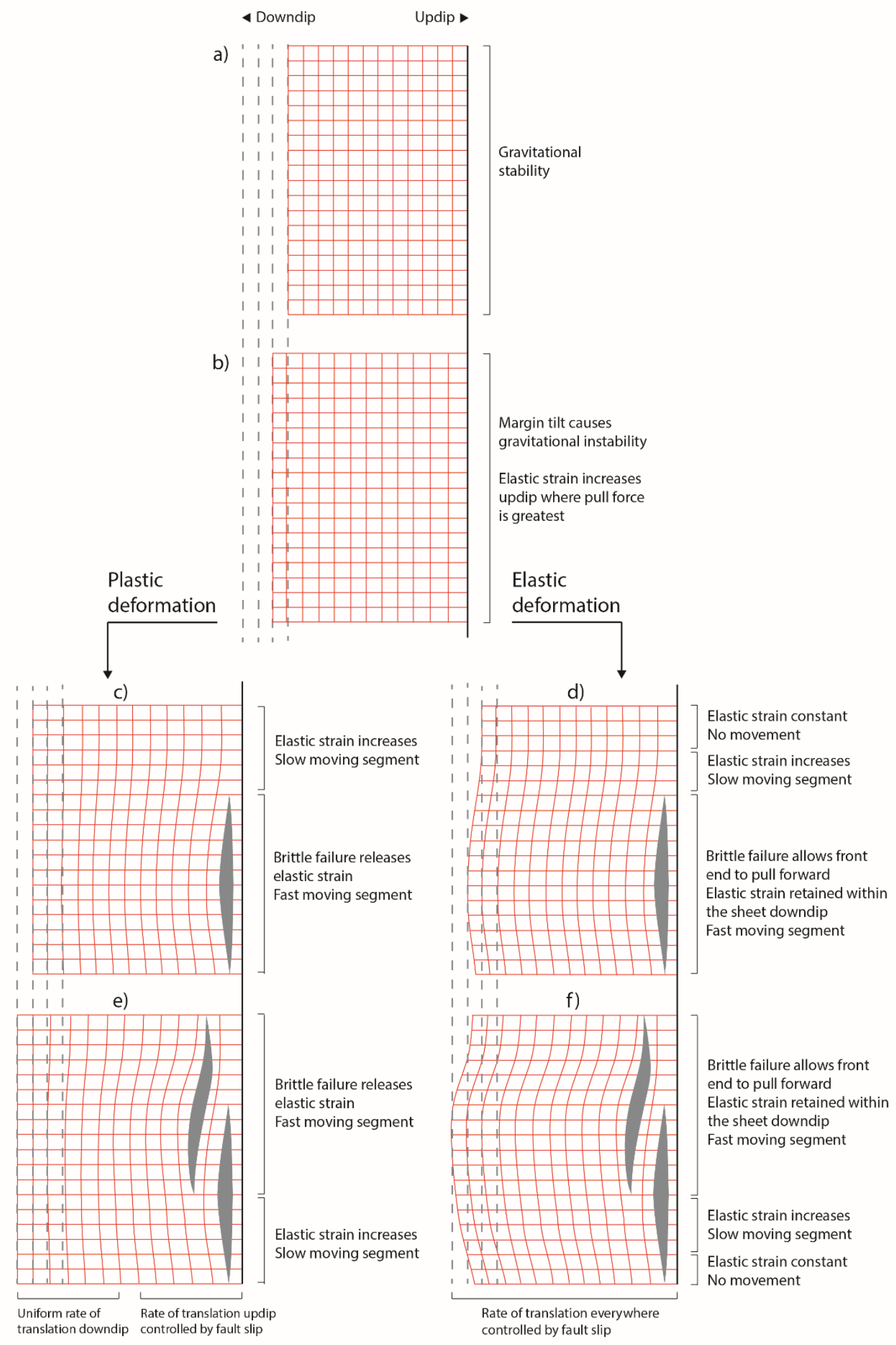

815 Figure 16 Schematic showing two models for elastic strain build-up and release within the overburden. 816 A dominantly plastic overburden allows the translational domain to pull away at a uniform rate and 817 the faults in the updip domain rupture as and when they reach a critical stress, locally releasing the 818 elastic strain build-up. A dominantly elastic overburden remains under tension and the ruptures updip 819 allow the sheet to pull forward by a magnitude dictated by the fault slip. 